\title{
Complexity in Data-Driven Fuzzy Inference Systems: Survey, Classification and Perspective
}

\author{
Jolanta MILIAUSKAITÉ ${ }^{1}$ and Diana KALIBATIENE ${ }^{2}$ \\ ${ }^{1}$ Institute of Data Science and Digital Technologies, Vilnius University, Akademijos str. 4, \\ Vilnius, LT-08663, Lithuania \\ ${ }^{2}$ Vilnius Gediminas Technical University, Sauletekio al. 11, Vilnius, LT-10223, Lithuania \\ jolanta.miliauskaite@mif.vu.lt, diana.kalibatiene@vgtu.lt
}

\begin{abstract}
Nowadays, data-driven fuzzy inference systems (FIS) have become popular to solve different vague, imprecise, and uncertain problems in various application domains. However, plenty of authors have identified different challenges and issues of FIS development because of its complexity that also influences FIS quality attributes. Still, there is no common agreement on a systematic view of these complexity issues and their relationship to quality attributes. In this paper, we present a systematic literature review of 1340 scientific papers published between 1991 and 2019 on the topic of FIS complexity issues. The obtained results were systematized and classified according to the complexity issues as computational complexity, complexity of fuzzy rules, complexity of membership functions, data complexity, and knowledge representation complexity. Further, the current research was extended by extracting FIS quality attributes related to the found complexity issues. The key, but not all, FIS quality attributes found are performance, accuracy, efficiency, and interpretability.
\end{abstract}

Keywords: membership function, fuzzy rule, fuzzy inference system, FIS, issue, complexity, quality attribute

\section{Introduction}

Nowadays, data-driven fuzzy inference systems (FIS) become popular to solve different vague, imprecise and uncertain problems, like prediction (Lee, 2019), network vulnerability evaluation (Fan et al., 2019), data classification (Ravi and Khare, 2018), (Harandi and Derhami, 2016), image processing (Ananthi et al., 2016), data granularity (Zhu et al., 2018), forecasting (Lou and Dong, 2012), etc. The development of such FIS involves dataset usage for automatic generation of membership functions and fuzzy rules used for inferencing or assessment. In FIS development using data-driven approach a fuzzy model (i.e., MF and fuzzy rules) can be learned quite efficiently and needs less expert input, (i.e., potentially biased human information is minimized) (Nasiri at al., 2011; McKay and Harris, 2016).

The literature presents different techniques for FIS development (Askari, 2017), (Ruiz-Garcia et al., 2019), (Lee, 2019). It highlights numerous challenges and issues related to its complexity, like the rule base complexity (Antonelli et al., 2010), data complexity (Alcalá et al., 2009), a large number of linguistic terms (Askari, 2017), 
(Ephzibah, 2011), etc. However, those complexity issues are not investigated sufficiently in a comprehensive way. In the analysed papers, authors have focused on a particular one or two issues separately, like computational complexity (Ruiz-Garcia et al., 2019), (Zhu et al., 2018), membership function (MF) complexity (Fan et al., 2019), (Ibarra et al., 2015), fuzzy rules complexity (Harandi and Derhami, 2016), (Bouchachia and Vanaret, 2014), etc. This lack of understanding of a general situation hampers progress in the field since academics offer a limited approach (Ivarsson and Gorschek, 2011).

Moreover, these complexity issues influence FIS quality attributes (Wohlin, 1996, December), (Nguyen-Duc, 2017). Still, there is no common agreement on a systematic view of these FIS complexity issues and their relationship to FIS quality attributes. Therefore, it is not clear which FIS complexity issues influence quality attributes. Knowing the proper quality attributes in FIS context would be beneficial for FIS development.

The main research question of this review is - What are the complexity issues in FIS? (RQ1). The further extension of RQ1 is RQ2 as the following: Which FIS quality attributes are influenced by FIS complexity issues?

In order to answer RQ1, a systematic literature review (SLR) is carried out. Consequently, to answer RQ2 and to determine the relationship between FIS quality attributes and FIS complexity issues, the extraction of FIS quality attributes related to the found complexity issues is performed in this paper. This research has two purposes and contributions. It is used to determine the possible set of complexity issues first, and, second, FIS quality attributes related to the found FIS complexity issues. The rest of this paper is structured as follows. Section 2 introduces complexity in FIS and explains the use of this concept in this paper. Section 3 presents the review method. Section 4 shows the obtained results of SLR. Section 5 discusses the paper results, answers the questions RQ1 and RQ2, and concludes the paper.

This paper is an extension of work originally presented in conference name (Miliauskaite and Kalibatiene, 2020a).

\section{Related work}

In this research, we have viewed the complexity concept in the context of FIS, but not in general. Therefore, below in this section, we present the complexity concept analysed in the reviewed papers. Consequently, we view FIS quality attributes presented in the analysed related papers in the scope of the found complexity issues. However, since there are little studies on FIS quality attributes, but not software system quality attributes in general.

\subsection{Data-driven fuzzy inference system and its complexity issues}

According to (Askari, 2017; Guillaume, 2001), a data-driven Fuzzy Inference System (FIS) consists of the main components (Fig. 1) as follows:

- Data Collection and Pre-Processing (Data Component) component is responsible for crisp or linguistic datasets collecting from one or multiple Data Source/(-s) and its cleaning, organization and integration (Wang et al., 2017) for future data exploitation in the Fuzzification Mechanism.

- Fuzzification Mechanism supports the application of numerous fuzzification methods. It converts the data input into fuzzy input. 


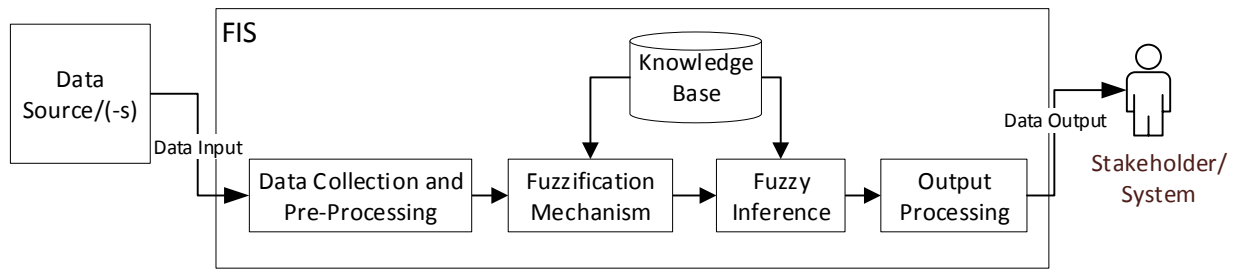

Fig. 1. The reference schema of a data-driven Fuzzy Inference System (FIS) (Miliauskaitè and Kalibatiene, 2020a).

- Knowledge Base is formed during the conversion of data input into fuzzy input, i.e., fuzzification. Consequently, it consists of a collection of MFs and fuzzy rules, used by the Fuzzy Inference component for inferencing.

- Fuzzy Inference component uses Knowledge Base and a particular fuzzy reasoning mechanism, like Mamdani or Takagi-Sugeno (T-S), to obtain a fuzzy output.

- Output Processing performs approximation, defuzzification and type reduction to convert the results of inferencing into output data (i.e., crisp or linguistic values), which should be optionally understandable to a Stakeholder or a System, which uses FIS output for its purpose.

The distinctive feature of FIS is that these systems are data-driven. MFs and fuzzy rules are generated from synthetic or real data streams (like data of measurements, etc.) automatically employing data clustering or other techniques instead of being defined by an expert, i.e., knowledge-driven (Adoko et al., 2013; Miliauskaitè and Kalibatiene, 2020b). This approach is commonly referred to as data-driven or fuzzy identification (Adoko et al., 2013). In order to ensure the accuracy of the rules derived from the data, they are interpreted and analysed. Consequently, some rules and MF can be modified or removed from FIS, or new rules may be added to FIS using expert knowledge, if required. A data-driven approach is usually employed in T-S FIS (Adoko et al., 2013). However, when inputs increase, the number of MFs and consequent rules increases exponentially (Adoko et al., 2013; Askari, 2017). As a result, missing, unnecessary and redundant rules are more likely to occur (Shill et al., 2015; Askari, 2017). Consequently, those rules interpretation is more complicated, and some of the rules may not correctly describe the physical problem being investigated (Adoko et al., 2013). Therefore, some authors, like (Adoko et al., 2013; Bashari et al., 2011), recommended using the datadriven approach when measured data of a given process exist, and formulating the fuzzy model based on expert knowledge is difficult.

The concept of complexity in FIS can be viewed from different perspectives. In (Antonelli et al., 2010), the rule base (RB) complexity is measured as the total number of conditions in the antecedents of the rules. Authors of (Antonelli et al., 2011a) understand complexity as interpretability of RB, and interpretability of fuzzy partitions as integrity of the database (DB). In (Alcalá et al., 2009), data complexity is measured in terms of the average number of patterns per variable (i.e., data density) for pattern recognition.

Complexity is also measured by counting the number of operations (Ephzibah, 2011) or number of elements in RB including the number of MFs, rules, premises, linguistic terms, etc. (Askari, 2017). Selecting a small number of linguistic terms and the right linguistic terms is essential for better interpretability. Total number of parameters of the fuzzy RB is also a measure of interpretability. A system with less number of parameters 
is more interpretable and less complex (Ishibuchi and Nojima, 2009). In (Askari, 2017), (Kaynak et al., 2002), authors suggest reducing the exponential complexity of FIS by reducing the number of fuzzy (linguistic) terms or the number of fuzzy (linguistic) variables or both. According to (Antonelli et al., 2016), the model interpretability is measured in terms of complexity: "Complexity is affected by the number of features used for generating the model: the lower the number of features, the lower the complexity".

In (McCulloch et al., 2020) authors understand complexity as the increase of fuzzy sets, e.g., the union of multiple MFs instead of a single MF forms fuzzy sets. Authors of (Wang et al., 2020) analyse a sampled-data stabilization issue for T-S fuzzy systems with state delays and nonuniform sampling. In a real-time hardware application, the computational complexity of an algorithm becomes a critical issue (Velusamy and Pugalendhi, 2020). Consequently, as authors of (Velusamy and Pugalendhi, 2020) state, the amount of computational requirement increases with the number of operations. Therefore, authors propose simultaneous evaluation of MFs and the rule set according to decision variables using the water cycle algorithm that results in a compact rule set and identification of an optimal path, and, consequently, consistently reduces the computational overhead. According to (Chiang et al., 2010; Miriyala et al., 2018; Yildiz, 2013), the presence of a large volume data leads to the rise of the number of MFs that need to be computed. This makes complex to implement FIS.

\subsection{FIS quality attributes}

Nowadays, there are numerous works analysing software quality attributes. In this research, we emphasize on FIS quality attributes related to the found complexity issues.

Primary for our study, we have used ISO/IEC/IEEE International Standard (ISO/IEC/IEEE, 2017) as a unified source for the meaning of a software system quality attributes. However, we have not derived and specified definitions of all possible software systems quality attributes not to limit or point in our research's wrong direction.

According to (Febrita et al., 2017), an excellent interpretable FIS meets the criteria as the following: 1) fuzzy set transparency, 2) simplicity of fuzzy rules, and 3) simplicity of the fuzzy model. The fuzzy set transparency ensures that each fuzzy sets are distinct and have distinguishable differences, i.e., the fuzzy sets overlapping is minimized. The simplicity of the fuzzy rules talks about the type of rules used (Febrita et al., 2017), i.e., a number of OR, product, etc. in composing rules. Therefore, to obtain a simpler FIS, the types of rules should be simplified, like in (Gegov et al., 2017) it is proposed several inconsistent rules replace by a single equivalent rule, to optimize parameters of a composite rule (Ma et al., 2017), or rules optimization (Dhebar and Deb, 2020). The fuzzy model's simplicity is determined by the number of inputs and inference rules. The more inference rules are contained in FIS, the more complicated the system will be (Febrita et al., 2017). Consequently, that FIS will lack interpretability. That is, the inference ruleset should be sparse (Tan et al., 2016; Huang and Shen, 2008). Consequently, removing those rules, which can be approximated by their neighbours, allows us to reduce FIS complexity (Tan et al., 2016). The same can be said about the simplicity of the input dataset, i.e., the more complete and compact dataset is used, the simpler the resulting FIS is obtained from this dataset. Unfortunately, modern datasets are huge, sparse or high dimensional (Chaudhuri, 2014; Soua et al., 2013; Lucas et al., 2012; Luo et al., 2019), has wide-range characteristic (Chen et al., 2020), etc.

In the analysed papers, some authors mention FIS attributes affected by its complexity. In (Marimuthu et al., 2019), the optimal number of fuzzy rules allows to 
achieve an accuracy rate of $95,8 \%$ and to reduce the computational complexity by triggering less number of rules. As stated in (Altilio et al., 2018), the optimal number of fuzzy rules and MFs, estimated using a Regularized Least Squares algorithm and following a procedure based on sparse Bayesian learning theory, allows to achieve better FIS effectiveness. Authors of (Ravi and Khare, 2018) optimize MFs and fuzzy rules using the exponential brainstorm optimization algorithm that allows utilizing them effectively for data classification. The proposed approach obtained the accuracy of $88,8 \%$, which is higher in comparison with the existing adaptive genetic FIS. In (Golestaneh et al., 2018), authors aim is to significantly reduce the neural network complexity by reducing the number of linear learning parameters, and to decrease the sensitivity while the acceptable accuracy and generalization performances are preserved. Askari (2017) proposed a novel Multiple-Input and Multiple-Output Clustering based FIS that satisfies the interpretability criteria.

Summing up, based on the related work, FIS complexity occurs in each component of FIS (see Fig. 1). However, there is no research analysing FIS complexity in a systematic way. Moreover, there is no common agreement on a systematic view of FIS complexity issues and their relationship to FIS quality attributes.

\section{Review method}

The review method was developed and executed according to the guidelines and hints provided by (Kitchenham and Charters, 2007; Kitchenham et al, 2009). The structure of the method is adapted from (Dybå and Dingsøyr, 2008) and its general schema is presented in Fig. 2.

\subsection{Defining research questions and scope}

Questions Formulation: the main question focus (RQ1) is related to the complexity issues of FIS. The secondary research focus is concerned with the FIS quality attributes related to the found FIS complexity issues.

Keywords and Synonyms: membership function, develop*, generat*, construct*, issue*, limit*, complex*.

Effect: Description of different FIS development complexity issues; visualisation of statistics by diagrams, view integration.

Studies Language: English.

Studies Type Definition: Journal publications (articles - A) and proceeding papers (PP).

Searching sources evaluation: As the study is focused on complexity issues of FIS, relevant papers should be searched in databases covering Computer Science (CS), Information Systems (IS), and Software Engineering (SE).

The Web of Science (WoS) database was chosen for the analysis, since it covers a wider range of refined and not duplicating researches. Moreover, the initial study of sources shows that it contains a significant number of papers relevant to the research questions. It enables us to find the most suitable and complete high-quality refereed studies for our research. WoS indexes high-quality peer-reviewed papers from the most relevant digital libraries for computer science, including journal and conference papers from IEEE Xplore, Springer Link, Science Direct, and ACM. 


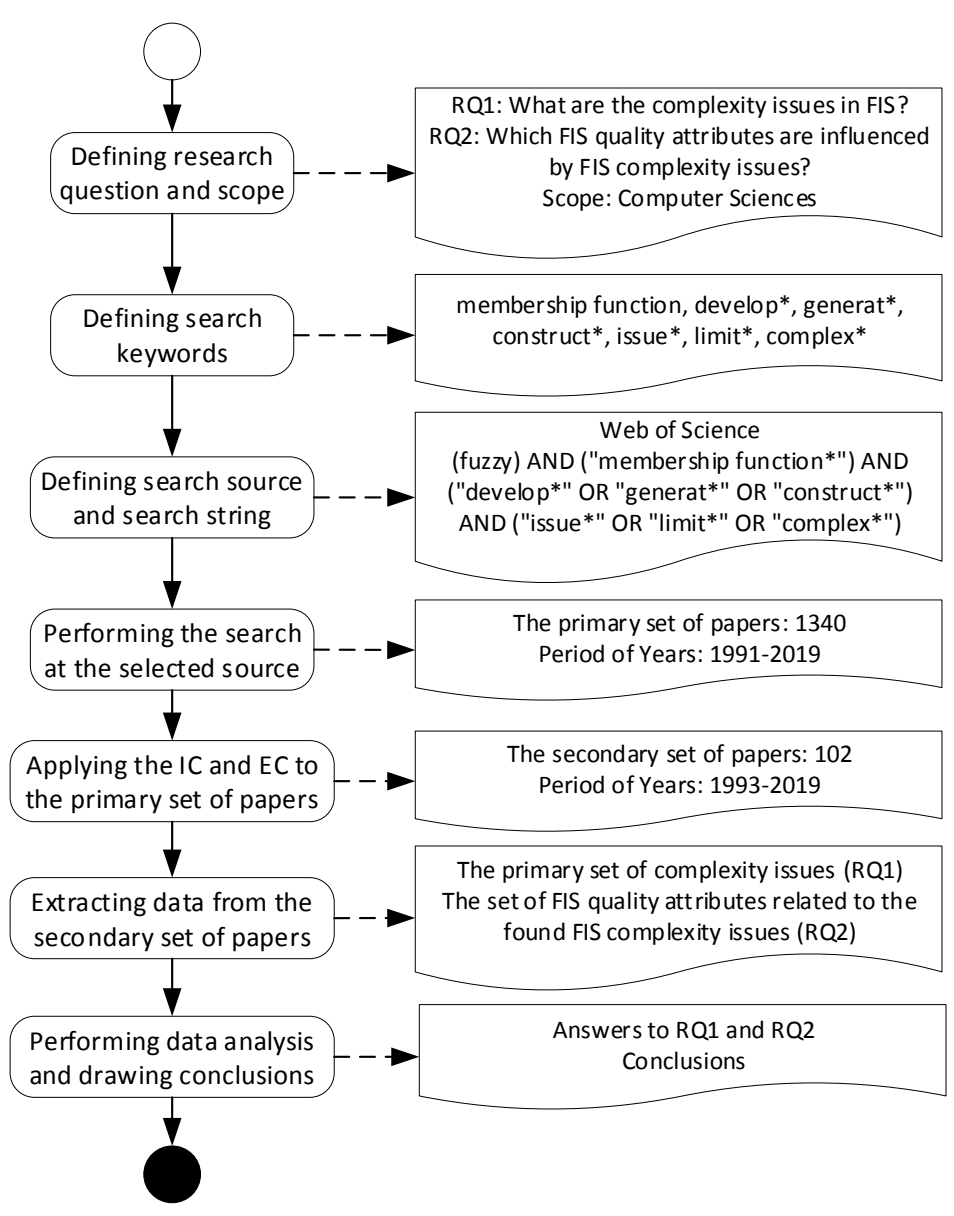

Fig. 2. The schema of the review method.

WoS and Scopus databases are not overlapping only $12,2 \%$ of documents in Engineering and Computer Science (Martín-Martín et al., 2018). WoS has an Impact Factor (IF), which is calculated to assess the quality of publications and the level of scientific research in close fields of knowledge. Moreover, WoS presents an easy mechanism to export the search results in different formats, supported by various reference management software, like Mendeley ${ }^{1}$, EndNote ${ }^{2}$, etc., and bibliometric tools, like VOSviewer ${ }^{3}$, CiteSpace ${ }^{4}$, etc.

The main keywords, their synonyms and the search string: the main keywords and their synonyms are presented in Table 1.

\footnotetext{
${ }^{1} \mathrm{https}: / / \mathrm{www} . \mathrm{mendeley} . \mathrm{com} /$ ?interaction_required=true

${ }^{2}$ https://endnote.com/

${ }^{3}$ https://www.vosviewer.com/

${ }^{4}$ http://cluster.cis.drexel.edu/ cchen/citespace/
} 
The finally developed search string: (fuzzy) AND ("membership function*") AND ("develop*" OR "generat*" OR "construct*") AND ("issue*" OR "limit*" OR "complex*")

Table 1. Keywords used for the search string.

\begin{tabular}{|c|c|c|}
\hline Main concepts & Related terms & Keywords used in the search \\
\hline Fuzzy Inference System & fuzzy system, FIS & fuzzy* \\
\hline membership function & function, MF & membership function* \\
\hline complex & issue, limitation & issue*, limit*, complex* $^{*}$ \\
\hline development & construction, generation & develop*, generat*, construct* $^{*}$ \\
\hline
\end{tabular}

\subsection{Studies inclusion and exclusion criteria}

Here we present main criteria used for the studies inclusion or exclusion from the review.

\section{Studies Inclusion Criteria (IC):}

IC1: Universally accepted relevant fundamental works on MF development, MF generation, MF construction, FIS and issues, limitations or complexity.

IC2: Papers must be available to download.

Studies Exclusion Criteria (EC):

EC1: Exclude papers, which contain relevant keywords, but MF and FIS issues, limitations or complexity are not the main topic of the paper.

EC2: Exclude relevant sources that repeat ideas described in earlier works.

EC3: Exclude papers, whose length is less than 8 pages, since such short papers can present only a general idea, but not describe overall approach.

EC4: If there are several papers of the same authors with the similar abstract, i.e., one paper is an extension of another, the less extended (i.e., containing less pages) paper is excluded.

The main statistics of the search is presented in Table 2 and Fig. 3.

Table 2. Number of papers (Articles (A) and Proceedings Papers (PP)).

\begin{tabular}{|c|c|c|c|c|}
\hline & Years & A & PP & All \\
\hline The primary set of papers & $1991-2019$ & 864 & 476 & 1340 \\
\hline The secondary set of papers & $1993-2019$ & 79 & 23 & 102 \\
\hline
\end{tabular}

In Fig. 3, the trend of the research on the topic is illustrated. The number of papers on FIS application to solve different complex domain problems raised yearly. This increase of papers can be attributed to technological development and the need to solve uncertain and vague problems in different application domains. However, the issues related to the usage of FIS are analysed insufficiently (Table 2 and Fig. 3). 


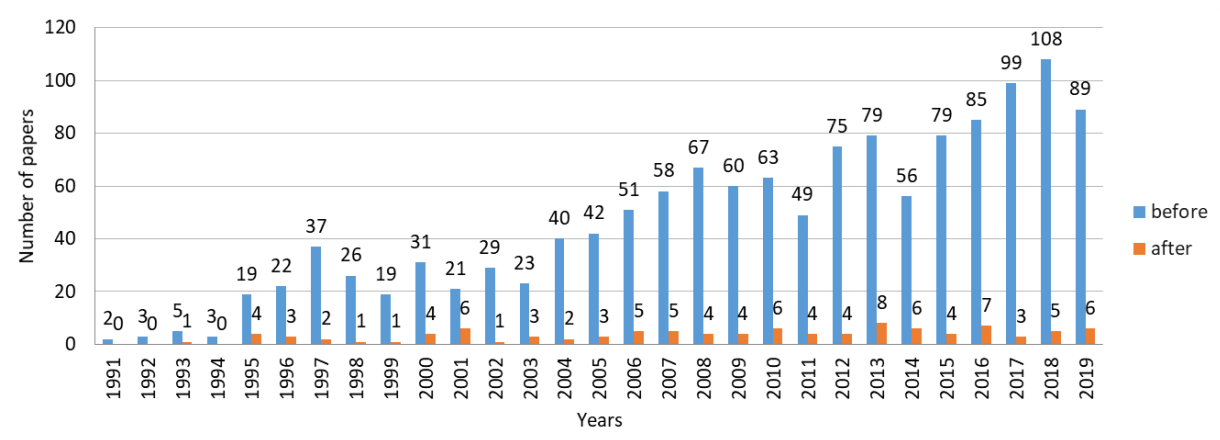

Fig. 3. Number of all papers before and after applying IC and EC.

\subsection{Threats to validity}

This section discusses the potential threats to validity of this SLR together with the actions we have taken to mitigate them. Although we carefully followed the SLR process (described in this section and presented in Fig. 2) to reduce the threats to the validity of the results and conclusions drawn in this paper, we faced some threats at their different stages that need further discussion.

Construct validity: When defining the SLR scope and keywords, we faced uncertainty about whether researchers refer to the FIS complexity issues or usage of FIS to solve particular tasks in a problem domain. Therefore, inclusion of the general keywords (like fuzzy inference system*, FIS, fuzzy system*, "complex*, issue) into the search string to cover all of the related papers generated an initial pool of 4357 papers. It mitigated the risk that the study setting does not reflect the construct under study, at the cost of adding additional manual efforts mainly when applying the inclusion and exclusion criteria. Consequently, a primary analysis of papers was done to familiarize with the FIS complexity issues and to define the related keywords more precisely. Some of the main related works are presented in Section 2.

When defining the searching strategy for paper selection, we faced two threats regarding the study's completeness, i.e., whether both (1) the searching sources and (2) the search string enabled all relevant papers to be retrieved. As mentioned previously, we used WoS since it enables us to find the most suitable, complete, and not duplicating high-quality refereed papers for our research. Second, for dealing with validity threats regarding the search string (i.e., missing keywords leading to the exclusion of relevant papers), we carried out the primary study during preparing (Miliauskaite and Kalibatiene, 2020a). The final search string was the conjunction of the keywords presented in Table 1 in the scope of CS.

Finally, we are aware that our study has a limitation related to coverage. The number of candidate papers might have been affected because (1) the search string might not be complete and might require additional or alternative terms, and (2) only one search strategy was used to select the candidate papers. These issues can be improved using different keywords thesauri, other search strategies, like snowballing or bibliometric analysis, or using more soft criteria for the papers inclusion and exclusion. However, considering the significant number of the primary set of papers (1 340), we consider that 
our results and findings are valuable for providing researchers and practitioners with an overview of the state of the art of FIS complexity issues.

Internal validity: Individual researcher's bias in (1) deciding whether to include or exclude a paper into the secondary set, (2) classifying it according to the complexity issues and FIS quality attributes, and (3) analysing the results make an internal threat to validity in this research that could lead to biased or erroneous conclusions. We took two main actions to minimize this threat. First, we have used a clearly defined searching strategy (see Fig. 2) to ensure a similar understanding. Second, both authors of this paper have assessed the obtained results (primary and secondary sets of papers) independently and combined the results.

External validity: A lack of consensus when researchers refer to the domain addressed in this study (e.g., the FIS complexity issues or usage of FIS to solve the particular issues in a problem domain) might lead to an inaccurate generalization in our findings. The results and conclusions of this SLR are only valid for the FIS, which understanding is described in Section 2. We have made great efforts to systematically set up the SLR protocol and apply it to ensure those general conclusions are valid irrespective of the lack of consensus highlighted.

\section{Results}

\subsection{Complexity issues in FIS (RQ1)}

The main results of our SLR according to RQ1 are presented in Table 3. It consists of six columns, five of which present the complexity issues found in the abstracts of the secondary set of papers. They are the following: (1) computational complexity (CC) (i.e., a huge number of calculations in all FIS components; algorithm complexity); (2) complexity of fuzzy rules (CFR) (i.e., extraction, modification and optimization of fuzzy rules); (3) complexity of MF (CMF) (i.e., MF development, optimization, simplification; partitioning; FOU definition; fuzzy numbers); (4) data complexity (DC) (i.e., a large number of input variables, incomplete data); and (5) knowledge representation complexity (CKR) (i.e., development of MF and RB issues). The secondary set of papers is presented in Annex $1^{5}$.

As can be seen from Table 3, complexity issues by their frequency of occurrence in the analyzed papers are distributed in descending order as the following. The most frequently found is the complexity of fuzzy rules ( 58 of 102 papers). The computational complexity ( 30 of 102 papers) and the complexity of MF ( 25 of 102 papers) were found in less than a third of the analyzed papers. The least occurred the knowledge representation complexity ( 13 of 102 papers) and the data complexity ( 7 of 102 papers).

Temporal distribution of five complexity issues found in the analysed papers included in the review are given in Fig. 4. The size of bubbles indicates the number of papers analysing each complexity issue per year. The larger the bubble, the more papers addressing the particular complexity issue.

As we can see from Fig. 4, the most relevant and constantly found complexity issue in FIS is complexity of fuzzy rules (CFR) (2) (58 of 102 papers). The second relevant complexity issue is computational complexity of FIS (CC) (1) (30 of 102 papers). The third relevant complexity issue is complexity of MF (CMF) (3) (25 of 102 papers).

\footnotetext{
${ }^{5}$ https://github.com/Jolantux13/Annex_BJMC
} 
Table 3. Complexity issues in FIS found in the abstracts of the secondary set of papers $(1-$ mentioned, 0 - not mentioned).

\begin{tabular}{|c|c|c|c|c|c|}
\hline References & (1) & (2) & (3) & (4) & (5) \\
\hline $\begin{array}{l}\text { (Ruiz-Garcia et al., 2019), (Lee, 2019), (Melin et al., 2019), } \\
\text { (Zhu et al., 2018), (Ananthi et al., 2016), (Chen et al., 2016), } \\
\text { (Ren et al., 2016), (Kumbasar and Hagras, 2015), } \\
\text { (Ramathilaga et al., 2014), (Zhu et al., 2013), (Murshid et al., } \\
\text { 2012), (Choi and Rhee, 2009), (Starczewski, 2009), (Lee and } \\
\text { Pan, 2009), (Nie and Tan, 2008), (Modi et al., 2007), (Pan et } \\
\text { al., 2007), (Hong et al., 2003), (Hsu and Szu, 2003), (Yao et } \\
\text { al., 2000), (Giachetti and Young, 1997), (Kóczy and Sugeno, } \\
\text { 1996) }\end{array}$ & 1 & 0 & 0 & 0 & 0 \\
\hline $\begin{array}{l}\text { (Fan et al., 2019), (Elkano et al., 2018), (Almasi and Rouhani, } \\
\text { 2016), (Ibarra et al., 2015), (Kaur et al., 2015), (Deng and } \\
\text { Yao, 2014), (Alaei et al., 2013), (Antonelli et al., 2011a), } \\
\text { (Tamir and Kandel, 2011), (Fateh, 2010), (Bridges et al., } \\
\text { 1995) }\end{array}$ & 0 & 0 & 1 & 0 & 0 \\
\hline $\begin{array}{l}\text { (Marimuthu et al., 2019), (Golestaneh et al., 2018), } \\
\text { (Chakraborty et al., 2013), (Kóczy and Botzheim, 2005), } \\
\text { (Marinelli et al., 1997) }\end{array}$ & 1 & 1 & 0 & 0 & 0 \\
\hline (Rajeswari and Deisy, 2019), (Sami et al., 2014) & 0 & 1 & 1 & 0 & 1 \\
\hline $\begin{array}{l}\text { (Altilio et al., 2018), (Ravi and Khare, 2018), (Askari, 2017), } \\
\text { (Pratama et al., 2013), (Antonelli et al., 2011), (Rania and } \\
\text { Deepa, 2010), (Antonelli et al., 2010), (Beldjehem, 2010), } \\
\text { (Zhou and Gan, 2008) }\end{array}$ & 0 & 1 & 1 & 0 & 0 \\
\hline $\begin{array}{l}\text { (Ge et al., 2017), (Antonelli et al., 2016), (Chaudhuri, 2014), } \\
\text { (Sanz et al., 2012), (Shill et al., 2011) }\end{array}$ & 0 & 0 & 0 & 1 & 0 \\
\hline (Dineva et al., 2017) & 0 & 1 & 1 & 1 & 1 \\
\hline $\begin{array}{l}\text { (Tan et al., 2016), (Harandi and Derhami, 2016), (Shill et al., } \\
\text { 2015), (Bouchachia and Vanaret, 2014), (GaneshKumar et } \\
\text { al., 2014), (Soua et al., 2013), (Samantaray, 2013), (Kumar et } \\
\text { al., 2013), (Ansari et al., 2013), (Chiu et al., 2012), (Kim et } \\
\text { al., 2010), (Leng et al., 2009), (Huang and Shen, 2008), (Feng } \\
\text { and Wong, 2008), (Liu et al., 2007), (Kenesei et al., 2007), } \\
\text { (González et al., 2007), (Xiong and Funk, 2006), (Kim et al., } \\
\text { 2006), (Zanganeh et al., 2006), (Huang and Shen, 2006), } \\
\text { (Casillas et al., 2005), (Kim and Ryu, 2005), (Baranyi et al., } \\
\text { 2004), (Kim and Ryu, 2004), (Xiong and Litz, 2002), } \\
\text { (Guillaume, 2001), (Alcalá et al., 2001), (Rojas et al., 2000), } \\
\text { (Lu, 1998), (Wang and Langari, 1996), (Castellano and } \\
\text { Fanelli, 1996), (Wang and Kim, 1995), (Rhee and } \\
\text { Krishnapuram, 1993) }\end{array}$ & 0 & 1 & 0 & 0 & 0 \\
\hline (Lou and Dong, 2012) & 1 & 0 & 0 & 0 & 1 \\
\hline (Al-Mamun and Zhu, 2010), (Matarazzo and Munda, 2001) & 0 & 0 & 1 & 0 & 1 \\
\hline $\begin{array}{l}\text { (Makrehchi et al., 2003), (Laukonen and Passino, 1995), } \\
\text { (Takagi et al., 1995) }\end{array}$ & 0 & 0 & 0 & 0 & 1 \\
\hline (Xiong, 2001), (Di et al., 2001), (Hsu and Chen, 2000) & 0 & 1 & 0 & 0 & 1 \\
\hline (Mitaim and Kosko, 2001), (Gil and Hwang, 2000) & 1 & 1 & 0 & 0 & 1 \\
\hline (Hong and Chen, 1999) & 0 & 1 & 0 & 1 & 0 \\
\hline
\end{tabular}

This issue has been addressed more intensively in analysed papers since 2010. The forth relevant complexity issue in FIS is knowledge representation complexity (CKR) (5) (13 
of 102 papers). Finally, the last relevant complexity issue is data complexity (DC) (4) (7 of 102 papers).

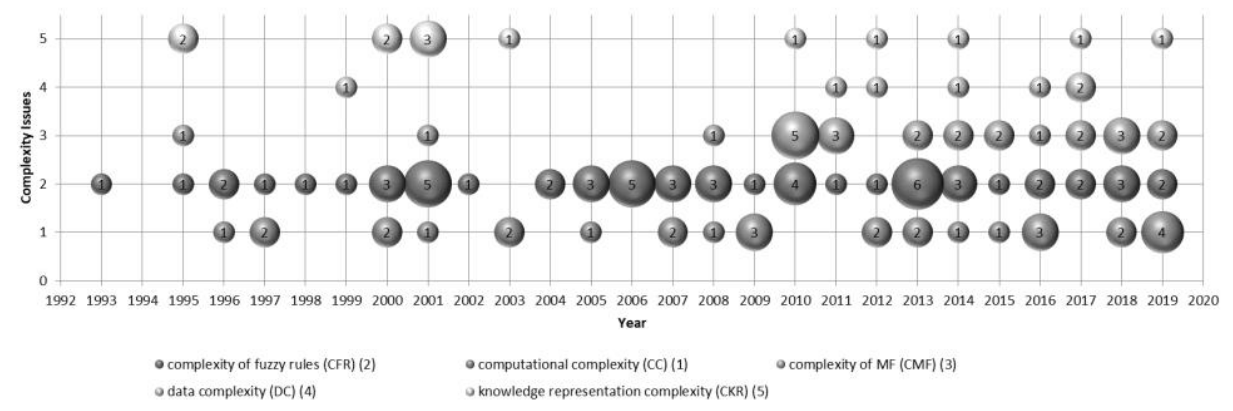

Fig. 4. Found complexity issues according to years.

\subsection{FIS quality attributes related to complexity issues (RQ2)}

The main results of our research according to RQ2 are presented in Table 4. It consists of one column presenting References of the analysed papers and seventeen columns presenting the found FIS quality attributes, which are the following:

1) Accuracy - the ability to approximate the outcome of the system accurately (Liu et al., 2007). Accuracy refers to the capability of the fuzzy model to represent the system faithfully (Casillas et al., 2003).

2) Interpretability - the ability to describe the behaviour of the system in an interpretable way (Liu et al., 2007). Interpretability refers to the capability of the fuzzy model to express the behaviour of the system in an understandable way (Casillas et al., 2003).

3) Performance - in general definition (Cortellessa et al., 2011), it measures how effective is a software system with respect to time constraints and allocation of resources. In the analysed papers, a part of authors explicitly mentioned realtime constraint, like real-time prediction (Lee, 2019), real-time control (Chen et al., 2016), online rule learning from real-time data streams ((Bouchachia and Vanaret, 2014), etc.

4) Robustness - as described in (Fernandez et al., 2005), robustness is the ability of a computer system to cope with errors during execution and erroneous input. In (Fateh, 2010), robustness is verified by performance of tracking error. Authors of (Nie and Tan, 2008) evaluated performance and robustness of their proposed fuzzy logic controller by changing coefficient values.

5) Flexibility - as presented in (IEEE Standards Coordinating Committee, 1990), flexibility (syn.: adaptability) is the ability of a system to be modified for use in applications or environments other than those for which it was specifically designed. In (Feng and Wong, 2008), authors understand flexibility in terms of turning MFs parameters and fuzzy rules according to the searching space. Authors of (Modi et al., 2007) understand flexibility as ability of a fuzzy system to form any number of clusters.

6) Efficiency - the degree to which a system performs its designated functions with minimum consumption of resources (Cortellessa et al., 2011). According 
to authors of (Rajeswari and Deisy, 2019), efficiency refers to cost-effective training. In the analysed papers, a number of authors mentioned effectiveness of their proposed FIS (see Fig. 5 and Table 4); however, they do not express directly what it means.

7) Stability - authors of (Zhu et al., 2013) investigated the problem of stabilization for nonuniform sampling FIS by combining characteristics of sampled-data systems with a Lyapunov-Krasovskii function that gives a less complex and less conservative stabilization criterion. Fateh (2010) analysed stability for fuzzy control of robot manipulators without knowing the explicit dynamics of a system.

8) User-friendliness - refers to ease of use as a primary objective (Cortellessa et al., 2011). In (Kóczy and Sugeno, 1996), authors mention that their FIS is userfriendly.

9) Transparency - refers to the ability of operating in such a way that it is easy for others to see what actions are performed. Authors of (González et al., 2007) and (Kenesei et al., 2007) link transparency with interpretability of FIS, i.e., they state that fuzzy rules should be transparent in order to stay interpretable FIS.

10) Compactness - based on (Cortellessa et al., 2011), compactness refers to be faster or shorter than the original system. Authors of (GaneshKumar et al., 2014) state that their proposed hybrid Ant Bee Algorithm generated FIS with highly interpretable and compact rules for all the data sets when compared with other approaches. In (Kim et al., 2006), authors investigate compactness of rules as well.

11) Adaptability - according to (Cortellessa et al., 2011), it is a synonym of flexibility. However, some authors use different terms for the same attribute. Therefore, it is left separately.

12) Integration - authors of (Cortellessa et al., 2011) refers to the combining of software components into an overall system. In FIS context, the integration refers to the combination of FIS with other approaches, like neural networks (Lee, 2019), an adaptive principal component analysis approach (Alaei et al., 2013), etc.

13) Self-organizing - according to (Di et al., 2001), adaptation of MFs and selforganizing of fuzzy rules are realized using self-learning and competitiveness of neural network. In (Hsu and Szu, 2003), authors used unsupervised learning algorithms, like the self-organizing algorithm, to derive MFs and fuzzy rules. Authors of (Rojas et al., 2000) proposed a self-organized fuzzy rule generation procedure.

14) Sensitivity - authors of (Ravi and Khare, 2018) analysed FIS sensitivity according to four datasets that refers to data-sensitive fault (Cortellessa et al., 2011), it is failure in response to some particular pattern of data). In (Golestaneh et al., 2018), authors aim to reduce the network complexity by reducing the number of linear learning parameters, and this reduces the sensitivity of FIS.

15) Reliability - refers to the ability of a system to perform its required functions under stated conditions for a specified period of time (Cortellessa et al., 2011). In (Zhou and Gan, 2008), authors named reliability as the main attribute of FIS as complex systems to model real-world systems.

16) Understandability - in (Zhou and Gan, 2008), it is related with reliability of complex systems. 
17) Validity - refers to the evaluation of the proposed approaches at the end of their development process to determine whether the system satisfies specified requirements, like (Rajeswari and Deisy, 2019), (Dineva et al., 2017), etc.

Table 4. FIS properties related to the found complexity issues in the secondary set of papers $(1-$ discussed in the abstract, 0 - not mentioned in the abstract).

\begin{tabular}{|c|c|c|c|c|c|c|c|c|c|c|c|c|c|c|c|c|c|}
\hline Reference & 1 & 2 & 3 & 4 & 5 & 6 & 7 & 8 & 9 & $\begin{array}{l}\mathbf{1} \\
\mathbf{0}\end{array}$ & $\begin{array}{l}\mathbf{1} \\
\mathbf{1}\end{array}$ & $\begin{array}{l}\mathbf{1} \\
\mathbf{2}\end{array}$ & $\begin{array}{l}\mathbf{1} \\
\mathbf{3}\end{array}$ & $\begin{array}{l}1 \\
4\end{array}$ & $\begin{array}{l}\mathbf{1} \\
\mathbf{5}\end{array}$ & $\begin{array}{l}1 \\
6\end{array}$ & $\frac{1}{7}$ \\
\hline (Lee, 2019) & 0 & 0 & 1 & 0 & 0 & 1 & 0 & 0 & 0 & 0 & 0 & 1 & 0 & 0 & 0 & 0 & 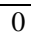 \\
\hline (Fan et al., 2019) & 0 & 0 & 1 & 0 & 0 & 0 & 0 & 0 & 0 & 0 & 0 & 0 & 0 & 0 & 0 & 0 & 0 \\
\hline (Marimuthu et al., 2019) & 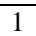 & 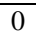 & 1 & 0 & 0 & , & 0 & 0 & 0 & 0 & & , & 0 & 0 & 0 & 0 & 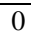 \\
\hline (Melin et al., 2019) & 0 & 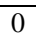 & 1 & 0 & 0 & 0 & 0 & 0 & 0 & 0 & 0 & 0 & 0 & 0 & 0 & 0 & 0 \\
\hline $\begin{array}{l}\text { (Rajeswari and Deisy, } \\
\text { 2019) }\end{array}$ & 1 & 0 & 0 & 0 & 0 & 4 & 0 & 0 & 0 & 0 & 0 & 0 & 0 & 0 & 0 & 0 & 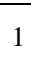 \\
\hline (Elkano et al., 2018) & 1 & 0 & 0 & 0 & 0 & 0 & 0 & 0 & 0 & 0 & 0 & 0 & 0 & 0 & 0 & 0 & 0 \\
\hline (Altilio et al., 2018) & , & 0 & 0 & 0 & 0 & 1 & 0 & 0 & 0 & 0 & 0 & 0 & 0 & 0 & 0 & 0 & $\Omega$ \\
\hline (Ravi and Khare, 2018) & 1 & 0 & 1 & 0 & 0 & 1 & 0 & 0 & 0 & 0 & 0 & 0 & 0 & 1 & 0 & 0 & $\Omega$ \\
\hline (Golestaneh et al., 2018) & 1 & 0 & 1 & 0 & 0 & 1 & 0 & 0 & 0 & 0 & 0 & 0 & 0 & 1 & 0 & 0 & 0 \\
\hline (Zhu et al., 2018) & 0 & 0 & 1 & 0 & 0 & 0 & 0 & 0 & 0 & 0 & 0 & 0 & 0 & 0 & 0 & 0 & 0 \\
\hline (Askari, 2017) & 0 & 1 & 0 & 0 & 0 & 0 & 0 & 0 & 0 & 0 & 0 & 0 & 0 & 0 & 0 & 0 & 0 \\
\hline (Dineva et al., 2017) & 1 & 0 & 1 & 0 & 0 & 0 & 0 & 0 & 0 & 0 & 1 & 0 & 0 & 0 & 0 & 0 & 1 \\
\hline lli et al., 2016 & 4 & 4 & 0 & 0 & 0 & . & 0 & , & 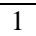 & 0 & , & 0 & 0 & 0 & 0 & 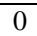 & 0 \\
\hline et al., 2016 & 0 & 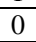 & 1 & 0 & 0 & 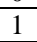 & 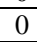 & 0 & 0 & 0 & 0 & 0 & 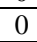 & 0 & 0 & & 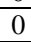 \\
\hline (Tan et al., 2016) & 1 & 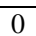 & 0 & 0 & 0 & 0 & 0 & 0 & 0 & 0 & 0 & 0 & 0 & 0 & 0 & 0 & 0 \\
\hline (Chen et al., 2016) & 1 & 0 & 1 & 0 & 0 & 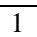 & 0 & 0 & 0 & 0 & 1 & 0 & 0 & 0 & 0 & 0 & 0 \\
\hline $\begin{array}{l}\text { (Almasi and Rouhani, } \\
\text { 2016) }\end{array}$ & 1 & 0 & 0 & 0 & 0 & 1 & 0 & 0 & 0 & 0 & 0 & 0 & 0 & 1 & 0 & 0 & 0 \\
\hline $\begin{array}{l}\text { (Harandi and Derhami, } \\
\text { 2016) }\end{array}$ & 1 & 0 & 0 & 0 & 0 & 0 & 0 & 0 & 0 & 0 & 0 & 0 & 0 & 0 & 0 & 0 & 0 \\
\hline (Shill et al., 2015) & 0 & 1 & 0 & 0 & 0 & 1 & 0 & 0 & 0 & 0 & 0 & 0 & 0 & 0 & 0 & 0 & 0 \\
\hline $\begin{array}{l}\text { (Kumbasar and Hagras, } \\
\text { 2015) }\end{array}$ & 0 & 0 & 1 & 0 & 0 & 0 & 0 & 0 & 0 & 0 & 0 & 1 & 0 & 0 & 0 & 0 & 0 \\
\hline (Kaur et al., 2015) & 0 & 0 & 1 & 1 & & 0 & 0 & 0 & $\mathrm{c}$ & 0 & 0 & 0 & 0 & 0 & 0 & j & 1 \\
\hline Yao, 2014) & 0 & 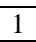 & , & 0 & & 0 & 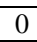 & 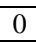 & 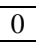 & 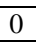 & 0 & 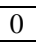 & 0 & 0 & 0 & 0 & 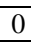 \\
\hline $\begin{array}{ll}\text { (Bouchachia } & \text { and } \\
\text { Vanaret, 2014) } & \end{array}$ & 0 & 0 & 1 & 0 & 0 & 0 & 0 & 0 & 0 & 0 & 0 & 0 & 0 & 0 & 0 & 0 & 1 \\
\hline (Sami et al., 2014) & 0 & 0 & 1 & 0 & 0 & 1 & 0 & 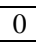 & 0 & 0 & 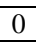 & 0 & 0 & 1 & 0 & 0 & 1 \\
\hline $\begin{array}{l}\text { (GaneshKumar et al., } \\
\text { 2014) }\end{array}$ & 1 & 1 & 1 & 0 & 0 & 0 & 0 & 0 & 0 & 1 & 0 & 0 & 0 & 0 & 0 & 0 & 0 \\
\hline (Chaudhuri, 2014) & 0 & 0 & 1 & 0 & 0 & 1 & 0 & 0 & 0 & 0 & 0 & 0 & 0 & 0 & 0 & 0 & 0 \\
\hline $\begin{array}{l}\text { (Ramathilaga et al., } \\
\text { 2014) }\end{array}$ & 1 & 0 & 1 & 0 & 0 & 1 & 0 & 0 & 0 & 0 & 0 & 0 & 0 & 0 & 0 & 0 & 1 \\
\hline al., 2013) & 0 & 0 & 0 & 0 & 0 & 1 & 1 & 0 & 0 & 0 & 0 & 0 & 0 & 0 & 0 & 0 & 0 \\
\hline (Chakraborty et al., 2013) & 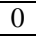 & 0 & 0 & 0 & & 1 & 0 & ( & $\mathrm{c}$ & 0 & 0 & 0 & 0 & 0 & 0 & 0 & 0 \\
\hline 2013) & 1 & 1 & 0 & 0 & 0 & 0 & 0 & 0 & - & 0 & 1 & 0 & 0 & 0 & 0 & 0 & 0 \\
\hline al., 2013) & 0 & 0 & 0 & 0 & 0 & 0 & 0 & 0 & 0 & 1 & 0 & 0 & 0 & 0 & 0 & 0 & 0 \\
\hline (Alaei et al., 2013) & 0 & 0 & 1 & 0 & 0 & 0 & 0 & 0 & 0 & 0 & 0 & 1 & 0 & 0 & 0 & 0 & 0 \\
\hline (Kumar et al., 2013) & 0 & 0 & 1 & 0 & 0 & 0 & 0 & 0 & 0 & 0 & 0 & 0 & 0 & 0 & 0 & 1 & 0 \\
\hline (Ansari et al., 2013) & 0 & 0 & 0 & 0 & 0 & 1 & 0 & 0 & 0 & 0 & 0 & 0 & 0 & 0 & 0 & 0 & 0 \\
\hline (Lou and Dong, 2012 & 1 & 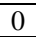 & 1 & 0 & T & 0 & 0 & 0 & 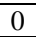 & 0 & 0 & 0 & 0 & 0 & 0 & 0 & 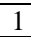 \\
\hline et al., 2012) & 0 & 0 & 1 & 0 & ( & 0 & 0 & 0 & 0 & 0 & 0 & 0 & 0 & 0 & 0 & 0 & 0 \\
\hline (Murshid et al., 2012) & 0 & 0 & 1 & 0 & 0 & 0 & 0 & 0 & 0 & 0 & 0 & 0 & 0 & 0 & 0 & 0 & 0 \\
\hline al., 2012) & 0 & 0 & 0 & 0 & 0 & 1 & 0 & 0 & 0 & 0 & 0 & 0 & 0 & 0 & 0 & 0 & 0 \\
\hline (Antonelli et al., 2011a) & 1 & 1 & 0 & 0 & 0 & 0 & 0 & 0 & 0 & 0 & 0 & 0 & 0 & 0 & 0 & 0 & 0 \\
\hline (Antonelli et al., 2011) & 1 & 1 & 0 & 0 & 0 & 0 & 0 & 0 & 0 & 0 & 0 & 0 & 0 & 0 & 0 & 0 & 0 \\
\hline (Tamir and Kandel, & 0 & 1 & 0 & 0 & 0 & 1 & 0 & 0 & 0 & 0 & 0 & 0 & 0 & 0 & 0 & 0 & 0 \\
\hline
\end{tabular}




\begin{tabular}{|c|c|c|c|c|c|c|c|c|c|c|c|c|c|c|c|c|c|}
\hline Reference & 1 & 2 & 3 & 4 & 5 & 6 & 7 & 8 & 9 & $\begin{array}{l}\mathbf{1} \\
\mathbf{0}\end{array}$ & $\mathbf{1}$ & $\begin{array}{l}1 \\
2\end{array}$ & $\begin{array}{l}\mathbf{1} \\
\mathbf{3}\end{array}$ & $\begin{array}{l}1 \\
4\end{array}$ & $\begin{array}{l}1 \\
5\end{array}$ & $\begin{array}{l}1 \\
6\end{array}$ & $\begin{array}{l}1 \\
7\end{array}$ \\
\hline \multicolumn{18}{|l|}{ 2011) } \\
\hline (Shill et al., 2011) & 0 & 0 & 1 & 0 & 0 & 1 & 0 & 0 & 0 & 0 & 0 & 1 & 0 & 0 & 0 & 0 & 0 \\
\hline (Rania and Deepa, 2010) & 0 & 0 & 1 & 0 & 0 & 0 & 0 & 0 & 0 & 0 & 0 & 0 & 0 & 0 & 0 & 0 & 0 \\
\hline (Kim et al., 2010) & 0 & 0 & 0 & 0 & 0 & 1 & 0 & 0 & 0 & 0 & 0 & 0 & 0 & 0 & 0 & 0 & 0 \\
\hline (Antonelli et al, 2010) & 1 & 0 & 0 & 0 & 0 & 0 & 0 & 0 & 0 & 0 & 0 & 0 & 0 & 0 & 0 & 0 & 0 \\
\hline (Beldjehem, 2010) & 0 & 0 & 0 & 0 & 0 & 0 & 0 & 0 & 0 & 0 & 0 & 1 & 0 & 0 & 0 & 0 & 0 \\
\hline (Fateh, 2010) & 0 & 0 & 0 & 1 & 0 & 0 & 1 & 0 & 0 & 0 & 0 & 0 & 0 & 0 & 0 & 0 & 0 \\
\hline (Leng et al., 2009) & 1 & 0 & 0 & 0 & 0 & 1 & 0 & 0 & 0 & 1 & 0 & 0 & 0 & 0 & 0 & 0 & 0 \\
\hline (Choi and Rhee, 2009) & 0 & 0 & 1 & 0 & 0 & 1 & 0 & 0 & 0 & 0 & 0 & 0 & 0 & 0 & 0 & 0 & 0 \\
\hline (Starczewski, 2009) & 0 & 0 & 0 & 0 & 0 & 1 & 0 & 0 & 0 & 0 & 0 & 0 & 0 & 0 & 0 & 0 & 0 \\
\hline (Lee and Pan, 2009) & 1 & 0 & 1 & 0 & 0 & 1 & 0 & 0 & 0 & 0 & 0 & 0 & 0 & 0 & 0 & 0 & 0 \\
\hline (Zhou and Gan, 2008) & 1 & 1 & 0 & 0 & 0 & 0 & 0 & 0 & 0 & 0 & 1 & 0 & 0 & 0 & 1 & 1 & 0 \\
\hline (Nie and Tan, 2008) & 0 & 0 & 0 & 1 & 0 & 0 & 0 & 0 & 0 & 0 & 0 & 0 & 0 & 0 & 0 & 0 & 0 \\
\hline (Feng and Wong, 2008) & 0 & 0 & 0 & 0 & 1 & 1 & 0 & 0 & 0 & 0 & 0 & 0 & 0 & 0 & 0 & 0 & 0 \\
\hline (Modi et al., 2007) & 0 & 0 & 1 & 0 & 1 & 0 & 1 & 0 & 0 & 0 & 0 & 0 & 0 & 0 & 0 & 0 & 0 \\
\hline (Liu et al., 2007) & 1 & 1 & 0 & 0 & 0 & 1 & 0 & 0 & 0 & 0 & 0 & 0 & 0 & 0 & 0 & 0 & 0 \\
\hline (Kenesei et al., 2007) & 0 & 0 & 1 & 0 & 0 & 0 & 0 & 0 & 1 & 0 & 0 & 0 & 0 & 0 & 0 & 0 & 0 \\
\hline (González et al., 2007) & 1 & 1 & 0 & 0 & 0 & 0 & 0 & 0 & 1 & 0 & 0 & 0 & 0 & 0 & 0 & 0 & 0 \\
\hline (Pan et al., 2007) & 1 & 0 & 1 & 0 & 0 & 1 & 0 & 0 & 0 & 0 & 0 & 0 & 0 & 0 & 0 & 0 & 0 \\
\hline (Kim et al., 2006) & 1 & 0 & 1 & 0 & 0 & 1 & 0 & 0 & 0 & 1 & 0 & 0 & 0 & 0 & 0 & 0 & 0 \\
\hline (Kim and Ryu, 2006) & 1 & 0 & 0 & 0 & 0 & 1 & 0 & 0 & 0 & 0 & 0 & 0 & 0 & 0 & 0 & 0 & 0 \\
\hline (Casillas et al., 2005) & 1 & 1 & 1 & 0 & 0 & 0 & 0 & 0 & 0 & 0 & 0 & 0 & 0 & 0 & 0 & 0 & 0 \\
\hline (Kim and Ryu, 2005) & 1 & 0 & 1 & 0 & 0 & 1 & 0 & 0 & 0 & 0 & 0 & 0 & 0 & 0 & 0 & 0 & 0 \\
\hline (Baranyi et al., 2004) & 0 & 1 & 0 & 0 & 0 & 1 & 0 & 0 & 0 & 0 & 0 & 0 & 0 & 0 & 0 & 0 & 0 \\
\hline (Kim and Ryu, 2004) & 0 & 0 & 1 & 0 & 0 & 1 & 0 & 0 & 0 & 0 & 0 & 0 & 0 & 0 & 0 & 0 & 0 \\
\hline (Hong et al., 2003) & 0 & 0 & 1 & 0 & 0 & 0 & 0 & 0 & 0 & 0 & 0 & 0 & 0 & 0 & 0 & 0 & 0 \\
\hline (Makrehchi et al., 2003) & 0 & 0 & 0 & 0 & 0 & 1 & 0 & 0 & 0 & 0 & 0 & 0 & 0 & 0 & 0 & 0 & 0 \\
\hline (Xiong and Litz, 2002) & 0 & 0 & 1 & 0 & 0 & 1 & 0 & 0 & 0 & 1 & 0 & 0 & 0 & 0 & 0 & 0 & 0 \\
\hline (Xiong, 2001) & 0 & 0 & 1 & 0 & 0 & 0 & 0 & 0 & 0 & 0 & 0 & 0 & 0 & 0 & 0 & 0 & 1 \\
\hline $\begin{array}{l}\text { (Mitaim and Kosko, } \\
\text { 2001) }\end{array}$ & 1 & 0 & 0 & 0 & 0 & 0 & 0 & 0 & 0 & 0 & 0 & 0 & 0 & 0 & 0 & 0 & 0 \\
\hline (Guillaume, 2001) & 1 & 1 & 0 & 0 & 0 & 0 & 0 & 0 & 0 & 0 & 0 & 0 & 0 & 0 & 0 & 0 & 0 \\
\hline (Di et al., 2001) & 1 & 0 & 1 & 0 & 0 & 1 & 0 & 0 & 0 & 0 & 1 & 0 & 1 & 0 & 0 & 0 & 0 \\
\hline $\begin{array}{l}\text { (Matarazzo and Munda, } \\
\text { 2001) }\end{array}$ & 0 & 0 & 0 & 0 & 0 & 0 & 0 & 0 & 0 & 0 & 0 & 1 & 0 & 0 & 0 & 0 & 0 \\
\hline (Alcalá et al., 2001) & 1 & 1 & 0 & 0 & 0 & 0 & 0 & 0 & 0 & 0 & 0 & 0 & 0 & 0 & 0 & 0 & 0 \\
\hline (Hsu and Chen, 2000) & 0 & 0 & 1 & 0 & 0 & 0 & 0 & 0 & 0 & 0 & 0 & 0 & 1 & 0 & 0 & 0 & 0 \\
\hline (Rojas et al., 2000) & 1 & 0 & 0 & 0 & 0 & 0 & 0 & 0 & 0 & 0 & 0 & 0 & 1 & 0 & 0 & 0 & 0 \\
\hline (Gil and Hwang, 2000) & 0 & 0 & 1 & 0 & 1 & 0 & 0 & 0 & 0 & 0 & 0 & 0 & 0 & 0 & 0 & 0 & 0 \\
\hline (Hong and Chen, 1999) & 0 & 0 & 0 & 0 & 0 & 1 & 0 & 0 & 0 & 0 & 0 & 0 & 0 & 0 & 0 & 0 & 0 \\
\hline$(\mathrm{Lu}, 1998)$ & 1 & 0 & 1 & 0 & 0 & 0 & 0 & 0 & 0 & 0 & 0 & 0 & 0 & 0 & 0 & 0 & 0 \\
\hline $\begin{array}{l}\text { (Giachetti and Young, } \\
\text { 1997) }\end{array}$ & 1 & 0 & 0 & 0 & 0 & 0 & 0 & 0 & 0 & 0 & 0 & 0 & 0 & 0 & 0 & 0 & 0 \\
\hline (Marinelli et al., 1997) & 0 & 0 & 1 & 0 & 0 & 0 & 0 & 0 & 0 & 0 & 0 & 0 & 0 & 0 & 0 & 0 & 0 \\
\hline $\begin{array}{l}\text { (Kóczy and Sugeno, } \\
1996)\end{array}$ & 0 & 0 & 0 & 0 & 0 & 0 & 0 & 1 & 1 & 0 & 0 & 0 & 0 & 0 & 0 & 0 & 0 \\
\hline $\begin{array}{l}\text { (Castellano and Fanelli, } \\
\text { 1996) }\end{array}$ & 1 & 1 & 0 & 0 & 0 & 0 & 0 & 0 & 0 & 0 & 0 & 0 & 0 & 0 & 0 & 0 & 0 \\
\hline $\begin{array}{l}\text { (Laukonen and Passino, } \\
\text { 1995) }\end{array}$ & 1 & 0 & 0 & 0 & 1 & 0 & 0 & 0 & 0 & 0 & 0 & 0 & 0 & 0 & 0 & 0 & 0 \\
\hline (Bridges et al., 1995) & 0 & 0 & 0 & 0 & 0 & 0 & 1 & 0 & 0 & 0 & 0 & 0 & 0 & 0 & 0 & 0 & 1 \\
\hline (Takagi et al., 1995) & 0 & 0 & 0 & 0 & 0 & 1 & 0 & 0 & 0 & 0 & 0 & 0 & 0 & 0 & 0 & 0 & 0 \\
\hline
\end{tabular}


As presented in Table 4, in the secondary set of papers not all authors mention FIS quality attributes in their abstracts. Therefore, those papers are excluded from the analysis of RQ2.

The most popular quality attributes found in the analysed papers (see Fig. 5) are the following: (3) performance (41 of 102 papers), (1) accuracy (37 of 102 papers), (6) efficiency (36 of 102 papers). Other thirteen found quality attributes are not so popular in the analysed papers: (2) interpretability (17 of 102 papers), (9) validity (9 of 102 papers), (11) adaptability (6 of 102 papers), (12) integration (6 of 102 papers), (5) flexibility (5 of 102 papers), (10) compactness (5 of 102 papers), (7) stability (4 of 102 papers), (9) transparency (4 of 102 papers), (14) sensitivity (4 of 102 papers), (4) robustness (3 of 102 papers), (13) self-organizing (3 of 102 papers), (16) understandability ( 2 of 102 papers), (8) user-friendliness (1 of 102 papers), and (15) reliability ( 1 of 102 papers).

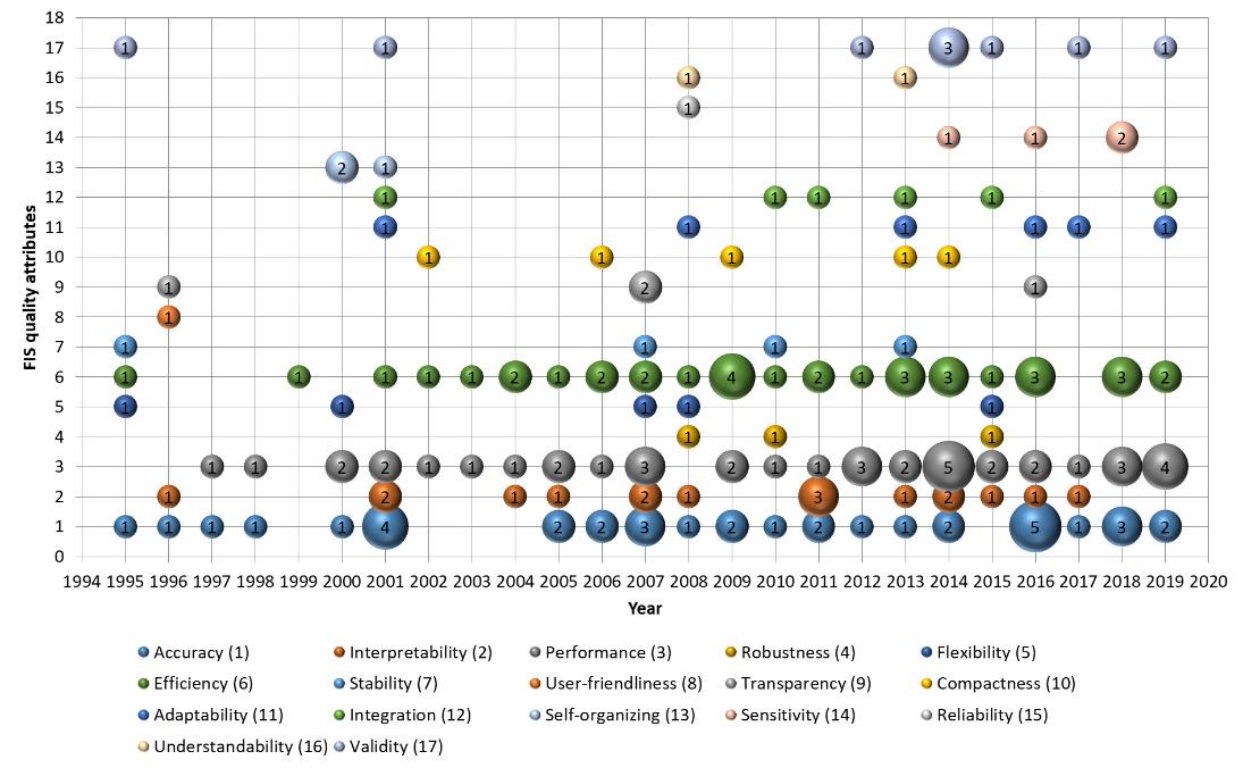

Fig. 5. Found FIS quality attributes according to years.

In Fig. 6, the relationship between FIS complexity issues and FIS quality attributes is presented. From the figure, we can see the following.

The computational complexity is related mostly with (3) performance (18 of 102 papers), (6) efficiency (11 of 102 papers), and (1) accuracy (9 of 102 papers). Meanwhile, (2) interpretability, (10) compactness, (13) self-organizing, (15) reliability and (16) understandability are not detected in relation with computational complexity. Other quality attributes are rarely found.

The complexity of fuzzy rules is found with (1) accuracy (26 of 102 papers), (6) efficiency (14 of 102 papers), (2) interpretability (6 of 102 papers), (3) performance (4 of 102 papers), and (16) understandability ( 1 of 102 papers). Other quality attributes have not been found in relation with the complexity of fuzzy rules. 
The complexity of MF is related with (1) accuracy ( 9 of 102 papers), (3) performance (7 of 102 papers), (2) interpretability (6 of 102 papers), (6) efficiency (6 of 102 papers) and (17) validity (5 of 102 papers). (8) User-friendliness, (9) transparency, and (13) selforganizing are not mentioned in the relationship with the complexity of MF. Other quality attributes are rarely detected in relation with complexity of MF.

The data complexity is found in relationship with (3) performance (4 of 102 papers), (6) efficiency ( 3 of 102 papers), and (1) accuracy ( 2 of 102 papers). (4) robustness, (5) flexibility, (7) stability, (8) user-friendliness, (10) compactness, (13) self-organizing, (14) sensitivity, (15) reliability, and (16) understandability are not found with the data complexity. Other quality attributes are rarely found in relation with data complexity.

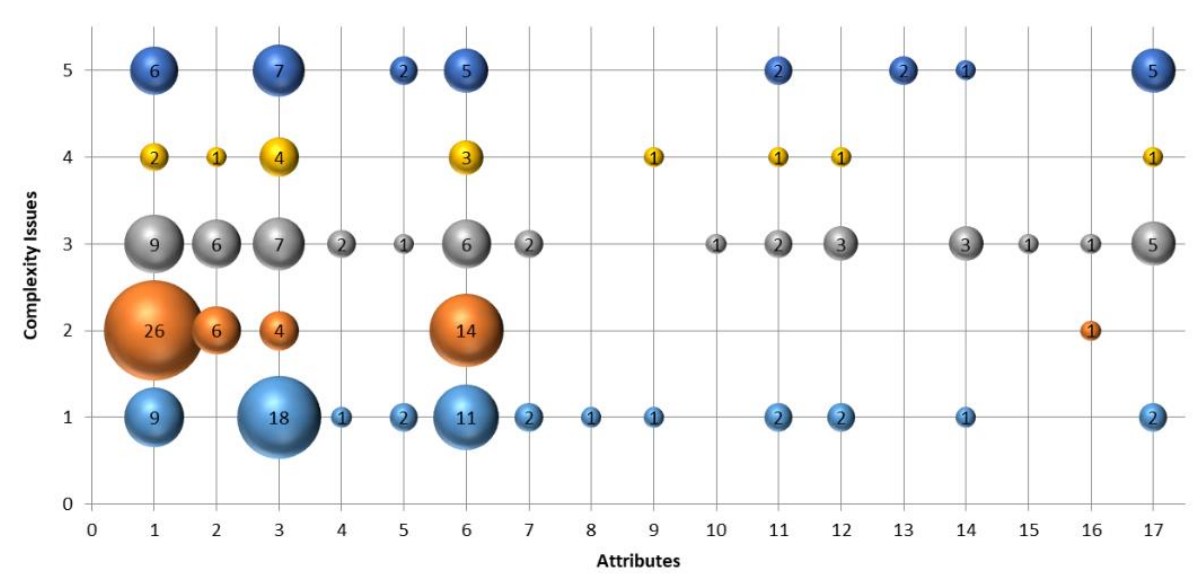

Fig. 6. Found FIS complexity issues and related FIS quality attributes (Attributes: (1) Accuracy, (2) Interpretability, (3) Performance, (4) Robustness, (5) Flexibility, (6) Efficiency, (7) Stability, (8) User-friendliness, (9) Transparency, (10) Compactness, (11) Adaptability, (12) Integration,

(13) Self-organizing, (14) Sensitivity, (15) Reliability, (16) Understandability, (17) Validity;

Complexity Issues: (1) computational complexity, (2) complexity of fuzzy rules, (3) complexity of MF, (4) data complexity, (5) knowledge representation complexity).

The knowledge representation complexity is mentioned with the following quality attributes: (3) performance (7 of 102 papers), (1) accuracy (6 of 102 papers), (6) efficiency (5 of 102 papers), and (17) validity (5 of 102 papers). Meanwhile, (5) flexibility, (11) adaptability, (13) self-organizing and (14) sensitivity are rarely found, and other quality attributes are not mentioned in relation with the knowledge representation complexity.

\section{Discussion and conclusions}

Finally, we can summarise the obtained results and answer to the research questions RQ1 (What are the complexity issues in FIS?) and RQ2 (Which FIS quality attributes are influenced by FIS complexity issues?).

Based on Table 3, five main issues are extracted from the analysed papers: (1) computational complexity, (2) complexity of fuzzy rules, (3) complexity of MF, (4) data 
complexity, and (5) knowledge representation complexity. Fig. 4 shows that the computational complexity (1) and complexity of fuzzy rules (2) were found in the analysed papers constantly throughout the analysed years (1993-2019). The complexity of MF (3) issue was found together with the computational complexity and complexity of fuzzy rules, and its analysis increase has been observed in the papers since 2010 . The relevance of these issues can be explained by the growth of technologies that generate increasing amounts of data. Therefore, the need to develop MFs from large data strings that requires high computational power is raised. The data complexity (4) issue becomes relevant since 2011. Its relevance can be explained by the emergence of big data, unstructured data and data-driven approach, and their usage in FIS. The knowledge representation complexity issue is weakly expressed directly. It is analysed in tandem with other issues, especially with the complexity of fuzzy rules, since it is recognized that rules are suitable to represent knowledge.

The complexity issues influence the following FIS quality attributes (RQ2): (1) accuracy, (2) interpretability, (3) performance, (4) robustness, (5) flexibility, (6) efficiency, (7) stability, (8) user-friendliness, (9) transparency, (10) compactness, (11) adaptability, (12) integration, (13) self-organizing, (14) sensitivity, (15) reliability, (16) understandability, and (17) validity. The most popular found quality attributes are the following: (3) performance, (1) accuracy, (6) efficiency, and (2) interpretability. Based on the founding we can conclude that FIS should perform effectively (i.e., produce the accurate outcome in an understandable and interpretable way) with respect to time constraints and allocation of resources. Other quality attributes are also important in FIS; however, not all authors say that directly, since the attributes vary according to the application domain and the problem being solved. Therefore, such quality attributes, as self-organizing, user-friendliness, etc., are more important in specific domains, like FIS integration with machine learning, etc.

The analysis of the relationship among complexity issues in FIS and FIS quality attributes shows that some FIS quality attributes are significantly influenced by complexity issues in FIS, as the following: 1) the computational complexity influences performance, efficiency and accuracy; 2) the complexity of fuzzy rules is related to accuracy, efficiency and interpretability; 3) the complexity of MF is related to accuracy, performance, interpretability, efficiency and validity; 4) the data complexity is related to performance, efficiency and accuracy; 5) the knowledge representation complexity is related to performance, accuracy, efficiency and validity. Other FIS quality attributes are less significant in the analysed papers. This could be an indicator that some quality attributes might be suitable in a certain FIS context only. This may need further investigation.

Summing up, in this paper we have presented the analysis of the complexity issues found in data-driven fuzzy inference systems (FIS). We have statistically described and discussed the found complexity issues in FIS. Moreover, FIS quality attributes related to the found complexity issues were observed in order to determine the relationship among them.

\subsection{Future works}

The proposed set of complexity issues in FIS is a first step toward the deeper understanding of the complexity of FIS, which can be extended applying root cause analysis technique. It constitutes a basis for discussion and for subsequent work in 
finding origins of complexity issues of FIS. Moreover, in the future research, we plan to develop a framework of complexity issues of FIS and their possible solutions.

According to the obtained results and identified future works, the need for automation of FIS development with the possibility to choose different levels of complexity of FIS arises. Since different domains require different FIS regarding quality attribute values, FIS of varying complexity levels is obtained as a final result. Moreover, developing FIS of particular complexity is a multi-criteria decision-making task since consensus among FIS quality attributes should be obtained.

\section{References}

Adoko, A. C., Gokceoglu, C., Wu, L., Zuo, Q. J. (2013). Knowledge-based and data-driven fuzzy modeling for rockburst prediction, International Journal of Rock Mechanics and Mining Sciences 61, 86-95.

Alaei, H., Salahshoor, K., Alaei, H. (2013). A new integrated on-line fuzzy clustering and segmentation methodology with adaptive PCA approach for process monitoring and fault detection and diagnosis, Soft Computing 17(3), 345-362.

Alcalá, R., Casillas, J., Cordón, O., Herrera, F. (2001). Building fuzzy graphs: features and taxonomy of learning for non-grid-oriented fuzzy rule-based systems, Journal of Intelligent \& Fuzzy Systems 11(3-4), 99-119.

Alcalá, R., Ducange, P., Herrera, F., Lazzerini, B., Marcelloni, F. (2009). A multiobjective evolutionary approach to concurrently learn rule and data bases of linguistic fuzzy-rule-based systems, IEEE Transactions on fuzzy systems 17(5), 1106-1122.

Al-Mamun, A., Zhu, Z. (2010). PSO-optimized fuzzy logic controller for a single wheel robot, in Vadakkepat, P. et al. (eds.), Proc. of Trends in Intelligent Robotics, FIRA 2010 Springer, Berlin, Heidelberg, 103, pp. 330-337.

Almasi, O. N., Rouhani, M. (2016). A new fuzzy membership assignment and model selection approach based on dynamic class centers for fuzzy SVM family using the firefly algorithm, Turkish Journal of Electrical Engineering \& Computer Sciences 24(3), 1797-1814.

Altilio, R., Rosato, A., Panella, M. (2018). A Sparse Bayesian Model for Random Weight Fuzzy Neural Networks, in Proc. of the 2018 IEEE Intern. Conf. on Fuzzy Systems (FUZZ-IEEE) (8-13 July 2018, Rio de Janeiro, Brazil), IEEE, pp. 1-7.

Ananthi, V. P., Balasubramaniam, P., Kalaiselvi, T. (2016). A new fuzzy clustering algorithm for the segmentation of brain tumor, Soft Computing 20(12), 4859-4879.

IEEE Standards Coordinating Committee. (1990). IEEE Standard Glossary of Software Engineering Terminology (IEEE Std 610.12-1990), Los Alamitos, CA: IEEE Computer Society, 169.

Ansari, A., Biswas, R., Aggarwal, S. (2013). Neutrosophic classifier: An extension of fuzzy classifer, Applied Soft Computing 13(1), 563-573.

Antonelli, M., Ducange, P., Lazzerini, B., Marcelloni, F. (2010). Exploiting a three-objective evolutionary algorithm for generating Mamdani fuzzy rule-based systems, in Proc.of the 2010 IEEE Intern. Conf. on Fuzzy Systems (FUZZ-IEEE), (18-23 July 2010, Barcelona, Spain), IEEE, pp. 1-8.

Antonelli, M., Ducange, P., Lazzerini, B., Marcelloni, F. (2011a). Learning knowledge bases of multi-objective evolutionary fuzzy systems by simultaneously optimizing accuracy, complexity and partition integrity, Soft Computing 15, 2335-2354.

Antonelli, M., Ducange, P., Lazzerini, B., Marcelloni, F. (2011). Learning concurrently data and rule bases of Mamdani fuzzy rule-based systems by exploiting a novel interpreta-bility index, Soft Computing 15(10), 1981-1998.

Antonelli, M., Ducange, P., Marcelloni, F., Segatori, A. (2016). On the influence of feature selection in fuzzy rule-based regression model generation, Information Sciences 329, 649669. 
Askari, S. (2017). A novel and fast MIMO fuzzy inference system based on a class of fuzzy clustering algorithms with interpretability and complexity analysis, Expert Systems With Applications 84, 301-322.

Baranyi, P., Kóczy, L., Gedeon, T. (2004). A generalized concept for fuzzy rule interpolation, IEEE Transactions on Fuzzy Systems 12(6), 820-837.

Bashari, A., Beiki, M., Talebinejad, A. (2011). Estimation of deformation modulus of rock masses by using fuzzy clustering-based modeling, International Journal of Rock Mechanics and Mining Sciences 48(8), 1224-1234.

Beldjehem, M. (2010). A unified granular fuzzy-neuro min-max relational framework for medical diagnosis, International Journal of Advanced Intelligence Paradigms 3(2), 122-144.

Bouchachia, A., Vanaret, C. (2014). GT2FC: An online growing interval type-2 self-learning fuzzy classifier, IEEE Transactions on Fuzzy Systems 22(4), 999-1018

Bridges, S., Higginbotham, C., McKinion, J., Hodges, J. (1995). Fuzzy descriptors of time-varying data: theory and application, International Journal of Artificial Intelligence 9(2), 1-14.

Casillas, J., Cordón, O., del Jesus, M., Herrera, F. (2005). Genetic tuning of fuzzy rule deep structures preserving interpretability and its interaction with fuzzy rule set reduction, IEEE Transactions on Fuzzy Systems 13(1), 13-29.

Casillas, J., Cordón, O., Herrera, F., Magdalena, L. (2003). Interpretability Improvements to Find the Balance Interpretability-Accuracy in Fuzzy Modeling: An Overview, in Casillas, J., Cordón, O., Ferrera, F., Magdalena, L. (eds.), Interpretability Issues in Fuzzy Modeling. Studies in Fuzziness and Soft Computing 128, Springer, pp. 3-22.

Castellano, G., Fanelli, A. (1996). Pruning in fuzzy-neural systems. Javor, A. (ed.), ESM, Soc. for Computer Simulation International, 673-677.

Chakraborty, A., Konar, A., Pal, N. R., Jain, L. C. (2013). Extending the contraposition property of propositional logic for fuzzy abduction. IEEE Transactions on Fuzzy Systems 21(4), 719734.

Chaudhuri, A. (2014). Modified fuzzy support vector machine for credit approval classification, $A I$ Communications 27(2), 189-211.

Chen, S., Lee, C., Wu, C., Hung, Y. (2016). Intelligent motion control of voice coil motor using PID-based fuzzy neural network with optimized membership function, Engineering Computations 33(8), 2302-2319.

Chen, Z., Sun, Y., You, D., Li, F., Shen, L. (2020). An accurate and efficient web service QoS prediction model with wide-range awareness, Future Generation Computer Systems 109, 275-292.

Chiang, C. W., Lee, W. P., Heh, J. S. (2010). A 2-Opt based differential evolution for global optimization, Applied Soft Computing, 10(4), 1200-1207.

Chiu, H.-P., Tang, Y.-T., Hsieh, K.-L. (2012). Applying cluster-based fuzzy association rules mining framework into EC environment, Applied Soft Computing 12(8), 2114-2122.

Choi, B.-I., Rhee, F.-H. (2009). Interval type-2 fuzzy membership function generation methods for pattern recognition, Information Sciences 179(13), 2102-2122.

Cortellessa, V., Di Marco, A., Inverardi, P. (2011). What Is Software Performance? Model-Based Software Performance Analysis, 1-7.

Deng, X., Yao, Y. (2014). Decision-theoretic three-way approximations of fuzzy sets, Information Sciences 279, 702-715.

Dhebar, Y., Deb, K. (2020). Interpretable Rule Discovery Through Bilevel Optimization of SplitRules of Nonlinear Decision Trees for Classification Problems, arXiv preprint, available at https://arxiv.org/abs/2008.00410.

Dybå, T., Dingsøyr, T. (2008). Empirical studies of agile software development: A systematic review, Information and Software Technology 50(9-10), 833-859.

Di, L., Srikanthan, T., Chandel, R., Katsunori, I. (2001). Neural-network-based self-organized fuzzy logic control for arc welding, Engineering Applications of Artificial Intelligence 14(2), $115-124$. 
Dineva, A., Várkonyi-Kóczy, A., Tar, J., Piuri, V. (2017). Performance enhancement of fuzzy logic controller using robust fixed point transformation. Recent Global Research and Education: Technological Challenges, in Jabłoński, R., Szewczyk, R. (eds.), Advances in Intelligent Systems and Computing, Vol. 519, Springer, Cham, pp. 411-418.

Elkano, M., Uriz, M., Bustince, H., Galar, M. (2018). On the usage of the probability integral transform to reduce the complexity of multi-way fuzzy decision trees in Big Data classification problems, in Proc. of the 2018 IEEE Intern. Congress on Big Data (BigData Congress) (2-7 Jul. 2018, San Francisco, CA), IEEE, pp. 25-32.

Ephzibah, E. (2011). Time complexity analysis of genetic- fuzzy system for disease diagnosis, Advanced Computing An International Journal 2(4), 23-31.

Fan, X., Li, C., Wang, Y. (2019). Strict intuitionistic fuzzy entropy and application in network vulnerability evaluation, Soft Computing 23(18), 8741-8752.

Fateh, M.-M. (2010). Robust fuzzy control of electrical manipulators, Journal of Intelligent \& Robotic Systems 60(3-4), 415-434.

Febrita, R. E., Alfiyatin, A. N., Taufiq, H., Mahmudy, W. F. (2017). Data-driven fuzzy rule extraction for housing price prediction in Malang. East Java, Bali, in Proc. of the 2017 Intern. Conf. on Advanced Computer Science and Information Systems (ICACSIS) (28-29 Oct. 2017, Bali, Indonesia), IEEE, pp. 351-358.

Feng, H.-M., Wong, C.-C. (2008). Fewer hyper-ellipsoids fuzzy rules generation using evolutional learning scheme, Cybernetics and Systems 39(1), 19-44.

Fernandez, J. C., Mounier, L., Pachon, C. (2005). A model-based approach for robustness testing, in Khendek, F., Dssouli, R. (eds.), Proc. of Testing of Communicating Systems. Proceedings of TestCom 2005 (31 May - 2 June 2005, Montreal, QC, Canada), Lecture Notes in Computer Science, 3502, Spreinger, Berlin, Heidelberg, pp. 333-348.

GaneshKumar, P., Rani, C., Devaraj, D., Victoire, T. (2014). Hybrid ant bee algorithm for fuzzy expert system based sample classification, IEEE/ACM Transactions on Computational Biology and Bioinformatics 11(2), 347-360.

Gegov, A., Sanders, D., Vatchova, B. (2017). Aggregation of inconsistent rules for fuzzy rule base simplification, International Journal of Knowledge-Based and Intelligent Engineering Systems 21(3), 135-145.

Ge, X., Wang, P., Yun, Z. (2017). The rough membership functions on four types of coveringbased rough sets and their applications, Information Sciences 390, 1-14.

Giachetti, R., Young, R. E. (1997). Analysis of the error in the standard approximation used for multiplication of triangular and trapezoidal fuzzy numbers and the development of a new approximation, Fuzzy Sets and Systems 91(1), 1-13.

Gil, J., Hwang, C.-S. (2000). A Design of Genetic-Fuzzy Systems Using Grammatical Encoding and Its Applications, in Mohammadian, M. (ed.), Proc. of Intern. Conf. on Computational Intelligence for Modelling, Control and Automation, New Frontiers in Computational Intelligence and Its Applications 57, IOS Press, Amsterdam, Oxford, pp. 178-187.

Golestaneh, P., Zekri, M., Sheikholeslam, F. (2018). Fuzzy wavelet extreme learning machine, Fuzzy Sets and Systems 342, 90-108.

González, J., Rojas, I., Pomares, H., Herrera, L.J., Guillen, A., Palomares, J.M., Rojas, F. (2007). Improving the accuracy while preserving the interpretability of fuzzy function approximators by means of multi-objective evolutionary algorithms, International Journal of Approximate Reasoning 44(1), 32-44.

Guillaume, S. (2001). Designing fuzzy inference systems from data: An interpretability-oriented review, IEEE Transactions on Fuzzy Systems 9(3), 426-443.

Harandi, F., Derhami, V. (2016). A reinforcement learning algorithm for adjusting anteced-ent parameters and weights of fuzzy rules in a fuzzy classifie, Journal of Intelligent \& Fuzzy Systems 30(4), 2339-2347.

Hong, T., Chen, J. (1999). Finding relevant attributes and membership functions, Fuzzy Sets and Systems 103(3), 389-404.

Hong, T., Lin, K., Chien, B. (2003). Mining fuzzy multiple-level association rules from quantitative data, Applied Intelligence 18(1), 79-90. 
Hsu, C., Szu, H. (2003). Chaotic neural network for learnable associative memory recall, in Bell, A.J., Wickerhauser, M.V., Szu, H.H. (eds.), Proc. of SPIE 5102, Independent Component Analyses, Wavelets, and Neural Networks 5102, pp. 258-266.

Hsu, Y., Chen, C. (2000). A novel fuzzy logic system based on N-version programming, IEEE Transactions On Fuzzy Systems 8(2), 155-170.

Huang, Z., Shen, Q. (2006). Fuzzy interpolative reasoning via scale and move transformations, IEEE Transactions On Fuzzy Systems 14(2), 340-359.

Huang, Z., Shen, Q. (2008). Fuzzy interpolation and extrapolation: A practical approach, IEEE Transactions On Fuzzy Systems 16(1), 13-28.

Yao, J., Dash, M., Tan, S. T., Liu, H. (2000). Entropy-based fuzzy clustering and fuzzy modeling, Fuzzy Sets and Systems 113(3), 381-388.

Ibarra, L., Rojas, M., Ponce, P., Molina, A. (2015). Type-2 Fuzzy membership function design method through a piecewise-linear approach, Expert Systems with Applications 42(21), 7530-7540.

Yildiz, A. (2013). Comparison of evolutionary-based optimization algorithms for structural design optimization, Engineering Applications of Artificial Intelligence 26(1), 327-333.

Ishibuchi, H., Nojima, Y. (2009). Discussions on Interpretability of Fuzzy Systems using Simple Examples, in Proc. of the Joint 2009 Intern. Fuzzy Systems Association World Congress and 2009 European Society of Fuzzy Logic and Technology Conference (2009 IFSA/EUSFLAT) (20-24 Jul. 2009, Lisbon, Portugal), pp. 1649-1654.

ISO/IEC/IEEE, (2017). ISO/IEC/IEEE International Standard - Systems and software engineering-Vocabulary. ISO/IEC/IEEE 24765:2017(E), 28 Aug. 1-541, available at https://ieeexplore.ieee.org/servlet/opac?punumber $=8016710$.

Ivarsson, M., Gorschek, T. (2011). A method for evaluating rigor and industrial relevance of technology evaluations, Empirical Software Engineering 16(3), 365-395.

Kaynak, O., Jezernik, K., Szeghegyi, A. (2002). Complexity reduction of rule based models: a survey, in Proc. of the 2002 IEEE Intern. Conf. on Fuzzy Systems. FUZZ-IEEE'02, Proc. (Cat. No.02CH37291) (12-17 May 2002, Honolulu, HI, USA) 2, IEEE, pp. 1216-1221.

Kaur, P., Kumar, S., Singh, A. (2015). Nature Inspired Approaches for Identification of Optimized Fuzzy Model: A Comparative Study, Journal of Multiple-Valued Logic and Soft Computing 25(4-5), 357-377.

Kenesei, T., Roubos, J., Abonyi, J. (2007). A combination-of-tools method for learning interpretable fuzzy rule-based classifiers from support vector machines, in Yin, H., Tino, P., Corchado, E., Byrne, W., Yao, X. (eds.), Proc. of the Intern. Conf. on Intelligent Data Engineering and Automated Learning - IDEAL 2007. IDEAL 2007. LNCS 4881, Springer, Berlin, Heidelberg, pp. 477-486.

Kim, D., de Silva, C. W., Park, G. (2010). Evolutionary design of Sugeno-type fuzzy sys-tems for modelling humanoid robots, International Journal of Systems Science 41(7), 875-888.

Kim, M., Ryu, J. (2004). Optimized fuzzy classification for data mining, in Lee, Y., Wang, K.-Y. (eds.), Proc. of the Intern. Conf. on Database Systems for Advanced Applications (DASFAA 2004) (17-19 March 2004, Jesu Island, Korea), LNCS 2973, Springer, Berlin, Heidelberg, pp. 582-593.

Kim, M., Ryu, J. (2005). Optimized fuzzy classification using genetic algorithm, in Wang, L., Jin, Y. (eds.), Proc. of the Intern. Conf. on Fuzzy Systems and Knowledge Discovery (FSKD 2005) (27-29 Aug. 2005, Changsha, China), LNCS 3613, Springer-Verlag, Berlin, Heidelberg, pp. 392-401.

Kim, M. W., Khil, A., Ryu, J. (2006). Efficient fuzzy rules for classification, in Ong, K.-L., SmithMiles, K., Ng, W.-K. (eds.), Proc. of the 1st Intern. Workshop on Integrating AI and Data Mining (AIDM'06) (4-5 Dec. 2006, Hobart, Tasmania, Australia), IEEE Computer Society, pp. 50-57.

Kim, M. W., Ryu, J. W. (2006). Optimized fuzzy decision tree using genetic algorithm, in King, I., Wang, J., Chan, L.W., Wang, D. (eds.), Proc. of the Intern. Conf. on Neural Information Processing (ICONIP 2006) (3-6 Oct. 2006, Hong Kong, China) 4234, Springer, Berlin, Heidelberg, pp. 797-806. 
Kitchenham, B., Brereton, O.B., Budgen, D., Turner, M., Bailey, J., Linkman, S. (2009). Systematic literature reviews in software engineering - A systematic literature review, Information and Software Technology 51(1), 7-15.

Kitchenham, B., Charters, S. (2007). Guidelines for Performing Systematic Literature Reviews in Software Engineering. Tech. Report. Version 2.3. EBSE Technical Report, EBSE-2007-01.

Kóczy, L., Botzheim, J. (2005). Fuzzy models, identification and applications, in Rudas, I.J. (ed.), Proc. of the IEEE $3^{\text {rd }}$ Intern. Conf. on Computational Cybernetics (ICCC 2005) (13-16 April 2005, Mauritius, Mauritius), IEEE, pp. 13-19.

Kóczy, L., Sugeno, M. (1996). Explicit functions of fuzzy control systems, International Journal of Uncertainty, Fuzziness and Knowledge-Based Systems 04(06), 515-535.

Kumar, P., Vijay, S., Devaraj, D. (2013). A hybrid colony fuzzy system for analyzing diabetes microarray data, in Proc. of the 2013 IEEE Symposium on Computational Intelligence in Bioinformatics and Computational Biology (CIBCB) (16-19 April 2013, Singapore, Singapore), pp. 104-111.

Kumbasar, T., Hagras, H. (2015). A self-tuning zSlices-based general type-2 fuzzy PI controller, IEEE Transactions on Fuzzy Systems 23(4), 991-1013.

Laukonen, E., Passino, K. (1995). Training fuzzy systems to perform estimation and identification, Engineering Applications of Artificial Intelligence 8(5), 499-514.

Lee, C.-H., Pan, H.-Y. (2009). Performance enhancement for neural fuzzy systems using asymmetric membership functions, Fuzzy Sets and Systems 160(7), 949-971.

Lee, R. (2019). Chaotic Interval Type-2 Fuzzy Neuro-oscillatory Network (CIT2-FNON) for Worldwide 129 Financial Products Prediction, International Journal of Fuzzy Systems 21(7), 2223-2244.

Leng, G., Zeng, X., Keane, J. (2009). A hybrid learning algorithm with a similarity-based pruning strategy for self-adaptive neuro-fuzzy systems, Applied Soft Computing 9(4), 1354-1366.

Liu, F., Quek, C., Ng, G. (2007). A novel generic hebbian ordering-based fuzzy rule base reduction approach to Mamdani neuro-fuzzy system, Neural Computation 19(6), 1656-1680.

Lou, C., Dong, M. (2012). Modeling data uncertainty on electric load forecasting based on Type-2 fuzzy logic set theory, Engineering Applications of Artificial Intelligence 25(8), 1567-1576.

Lucas, J. P., Laurent, A., Moreno, M. N., Teisseire, M. (2012). A fuzzy associative classification approach for recommender systems, International Journal of Uncertainty, Fuzziness and Knowledge-Based Systems 20(04), 579-617.

Luo, X., Wu, H., Yuan, H., Zhou, M. (2019). Temporal pattern-aware QoS prediction via biased non-negative latent factorization of tensors, IEEE Transactions on Cybernetics 50(5), 17981809.

Lu, P. (1998). The application of fuzzy neural network techniques in constructing an adaptive carfollowing indicator, Artificial Intelligence for Engineering Design, Analysis and Manufacturing 12(3), 231-241.

Ma, Y., Qiao, F., Zhao, F., Sutherland, J. W. (2017). Dynamic scheduling of a semiconductor production line based on a composite rule set, Applied Sciences 7(10), 1052.

Makrehchi, M., Basir, O., Kamel, M. (2003). Generation of fuzzy membership function using information theory measures and genetic algorithm, in Bilgiç, T., De Baets, B., Kaynak, O. (eds.), Proc. of the Fuzzy Sets and Systems - IFSA 2003. LNCS 2715, Springer, Berlin, Heidelberg, pp. 603-610.

Marimuthu, P., Perumal, V., Vijayakumar, V. (2019). OAFPM: optimized ANFIS using frequent pattern mining for activity recognition, The Journal of Supercomputing 75, 5347-5366.

Marinelli, C., Castellano, G., Attolico, G., Distante, A. (1997). Optimization of a fuzzy control-ler by genetic algorithms, Applications of Soft Computing 3165, 153-160.

Martín-Martín, A., Orduna-Malea, E., Thelwall, M., López-Cózar, E. (2018). Google Scholar, Web of Science, and Scopus: A systematic comparison of citations in 252 subject categories, Journal of Informetrics 12(4), 1160-1177.

Matarazzo, B., Munda, G. (2001). New approaches for the comparison of LR fuzzy numbers: a theoretical and operational analysis, Fuzzy Sets and Systems 118(3), 407-418. 
McCulloch, J., Ellerby, Z., Wagner, C. (2020). On the Relationship between Similarity Measures and Thresholds of Statistical Significance in the Context of Comparing Fuzzy Sets, IEEE Transactions on Fuzzy Systems 28(8), 1785-1798.

McKay, G., Harris, J. R. (2016). Comparison of the data-driven random forests model and a knowledge-driven method for mineral prospectivity mapping: A case study for gold deposits around the Huritz Group and Nueltin Suite, Natural Resources Research 25(2), 125-143.

Melin, P., Ontiveros-Robles, E., Gonzalez, C., Castro, J., Castillo, O. (2019). An approach for parameterized shadowed type-2 fuzzy membership functions applied in control applications, Soft Computing 23(11), 3887-3901.

Miliauskaite, J., Kalibatiene, D. (2020a). Complexity Issues in Data-Driven Fuzzy Inference Systems: Systematic Literature Review, in Robal, T., Haav, H., Penjam, J., Matulevičius, R. (eds.), Proc. of the $14^{\text {th }}$ Intern. Baltic Conf. on Databases and Information Systems (Baltic $D B \& I S$ 2020) (16-19 June 2020, Tallinn, Estonia), Communications in Computer and Information Science, 1243, Springer, Cham, pp. 190-204.

Miliauskaite, J., Kalibatiene, D. (2020b). On general framework of type-1 membership function construction: case study in QoS planning, International Journal of Fuzzy Systems 22(2), 504-521.

Miriyala, S., Subramanian, V., Mitra, K. (2018). TRANSFORM-ANN for online optimization of complex industrial processes: Casting process as case study, European Journal of Operational Research 264(1), 294-309.

Mitaim, S., Kosko, B. (2001). The shape of fuzzy sets in adaptive function approximation, IEEE Transactions on Fuzzy Systems 9(4), 637-656.

Modi, P., Singh, S., Sharma, J. (2007). Voltage stability evaluation of power system with FACTS devices using fuzzy neural network, Engineering Applications of Artificial Intelligence 20(4), 481-491.

Murshid, A., Loan, S., Abbasi, S., Alamoud, A. (2012). A novel VLSI architecture for a fuzzy inference processor using triangular-shaped membership function, International Journal of Fuzzy Systems 14(3), 345-360.

Nasiri, M., Hüllermeier, E., Senge, R., Lughofer, E. (2011). Comparing methods for knowledgedriven and data-driven fuzzy modeling: A case study in textile industry, in Proc. of the Intern. Fuzzy Systems Association World Congress (IFSA 2011), World Congress of the International Fuzzy Systems Association, Surabaya and Bali Island, Indonesia, RW-103-1-6.

Nguyen-Duc, A. (2017). The impact of software complexity on cost and quality - A comparative analysis between Open source and proprietary software, International Journal on Software Engineering and Application 8 (2), 17-31.

Nie, M., Tan, W. (2008). Towards an efficient type-reduction method for interval type-2 fuzzy logic systems, in Proc. of the 2008 IEEE Intern. Conf. on Fuzzy Systems (IEEE World Congress on Computational Intelligence) (1-6 June 2008, Hong Kong, China), IEEE, pp. 1425-1432.

Pan, H., Lee, C. H., Chang, F. K., Chang, S. K. (2007). Construction of asymmetric type-2 fuzzy membership functions and application in time series prediction, in Proc. of the 2007 Intern. Conf. on Machine Learning and Cybernetics (19-22 Aug. 2007, Hong Kong, China) 4, IEEE Service Center, pp. 2024-2030.

Pratama, M., Er, M.J., Li, X., Oentaryo, R.J., Lughofer, E., Arifin, I. (2013). Data driven modeling based on dynamic parsimonious fuzzy neural network, Neurocomputing 110, 18-28.

Rajeswari, A., Deisy, C. (2019). Fuzzy logic based associative classifier for slow learners prediction, Journal of Intelligent \& Fuzzy Systems 36(3), 2691-2704.

Ramathilaga, S., Jiunn-Yin Leu, J., Huang, K., Huang, Y. (2014). Two novel fuzzy clustering methods for solving data clustering problems, Journal of Intelligent and Fuzzy Systems 26(2), 705-719.

Rania, C., Deepa, S. (2010). PSO with mutation for fuzzy classifier design, Procedia Computer Science 2, 307-313.

Ravi, C., Khare, N. (2018). BGFS: Design and development of brain genetic fuzzy system for data classification, Journal of Intelligent Systems 27(2), 231-247. 
Ren, P., Xu, Z., Lei, Q. (2016). Simplified interval-valued intuitionistic fuzzy sets with intuitionistic fuzzy numbers, Journal of Intelligent \& Fuzzy Systems 30(5), 2871-2882.

Rhee, F., Krishnapuram, R. (1993). Fuzzy rule generation methods for high-level computer vision, Fuzzy Sets and Systems 60(3), 245-258.

Rojas, I., Pomares, H., Ortega, J., Prieto, A. (2000). Self-organized fuzzy system generation from training examples, IEEE Transactions on Fuzzy Systems 8(1), 23-36.

Ruiz-Garcia, G., Hagras, H., Pomares, H., Rojas, I. (2019). Towards a fuzzy logic system based on general forms of interval type-2 fuzzy sets, IEEE Transactions on Fuzzy Systems 27(12), 2381-2395.

Samantaray, S. (2013). A systematic fuzzy rule based approach for fault classification in transmission lines, Applied Soft Computing 13(2), 928-938.

Sami, M., Shiekhdavoodi, M., Pazhohanniya, M., Pazhohanniya, F. (2014). Environmental comprehensive assessment of agricultural systems at the farm level using fuzzy logic: a case study in cane farms in Iran, Environmental Modelling \& Software 58, 95-108.

Sanz, J., Bustince, H., Fernández, A., Herrera, F. (2012). IIVFDT: Ignorance functions based interval-valued fuzzy decision tree with genetic tuning, International Journal of Uncertainty Fuzziness and Knowledge-Based Systems 20(supp02), 1-30.

Shill, P., Akhand, M., Asaduzzaman, M., Murase, K. (2015). Optimization of fuzzy logic controllers with rule base size reduction using genetic algorithms, International Journal of Information Technology and Decision Making 14(5), 1063-1092.

Shill, P., Hossain, M., Amin, M., Murase, K. (2011). An adaptive fuzzy logic controller based on real coded quantum-inspired evolutionary algorithm, in Proc. of the 2011 IEEE Intern. Conf. on Fuzzy Systems (FUZZ-IEEE 2011), (27-30 June 2011, Taipei, Taiwan), IEEE, pp. 614621.

Soua, B., Borgi, A., Tagina, M. (2013). An ensemble method for fuzzy rule-based classification systems, Knowledge and Information Systems 36(2), 385-410.

Starczewski, J. (2009). Efficient triangular type-2 fuzzy logic systems, International Journal of Approximate Reasoning 50(5), 799-811.

Takagi, T., Imura, A., Ushida, H., Yamaguchi, T. (1995). Conceptual fuzzy sets as a meaning representation and their inductive construction, International Journal of Intelligent Systems 10(11), 929-945.

Tamir, D., Kandel, A. (2011). Axiomatic theory of complex fuzzy logic and complex fuzzy classes, Int. J. of Computers, Communications \& Control 6(3), 562-576.

Tan, Y., Li, J., Wonders, M., Chao, F., Shum, P.H., Yang, L. (2016). Towards sparse rule base generation for fuzzy rule interpolation, in Proc. of the 2016 IEEE Intern. Conf. on Fuzzy Systems (FUZZ-IEEE), (24-29 Jul. 2016, Vancouver, BC, Canada), pp. 110-117.

Velusamy, D., Pugalendhi, G. (2020). Water Cycle Algorithm Tuned Fuzzy Expert System for Trusted Routing in Smart Grid Communication Network, IEEE Transactions on Fuzzy Systems 28(6), 1167-1177.

Wang, F., Kim, H. (1995). Implementing adaptive fuzzy logic controllers with neural net-works: A design paradigm, Journal of Intelligent and Fuzzy Systems 3(2), 165-180.

Wang, H., Xu, Z., Pedrycz, W. (2017). An overview on the roles of fuzzy set techniques in big data processing: Trends, challenges and opportunities, Knowledge-Based Systems 118, 1530.

Wang, L., Langari, R. (1996). Sugeno model, fuzzy discretization, and the EM algorithm, Fuzzy Sets and Systems 82(3), 279-288.

Wang, X., Park, J. H., Yang, H., Zhao, G., Zhong, S. (2020). An improved fuzzy sampled-data control to stabilization of TS fuzzy systems with state delays, IEEE Transactions on Cybernetics 50(7), 3125-3135.

Wohlin, C. (1996, December). Revisiting measurement of software complexity, in Proc. of the 1996 Asia-Pacific Software Engineering Conference (4-7 Dec. 1996, Seoul, South Korea), IEEE, pp. 35-43.

Xiong, N. (2001). Evolutionary learning of rule premises for fuzzy modelling, International Journal of Systems Science 32(9), 1109-1118. 
Xiong, N., Funk, P. (2006). Construction of fuzzy knowledge bases incorporating feature selection, Soft Computing 10(9), 796-804.

Xiong, N., Litz, L. (2002). Reduction of fuzzy control rules by means of premise learning-method and case study, Fuzzy Sets and Systems 132(2), 217-231.

Zanganeh, M., Mousavi, S., Etemad-Shahidi, A. (2006). A genetic algorithm-based fuzzy inference system in prediction of wave parameters, in Reusch, B. (ed.), Proc.of Intern. Conf. 9th Fuzzy Days in Dortmund, Germany, Computational Intelligence, Theory and Applications (18-20 Sept. 2006, Dortmund, Germany), Springer-Verlag Berlin Heidelber, pp. 741-750.

Zhou, S. M., Gan, J. Q. (2008). Low-level interpretability and high-level interpretability: a unified view of data-driven interpretable fuzzy system modelling, Fuzzy Sets and Systems 159(23), 3091-3131.

Zhu, X.-L., Chen, B., Wang, Y., Yue, D. (2013). Ho stabilization criterion with less complexi-ty for nonuniform sampling fuzzy systems, Fuzzy Sets and Systems 225, 58-73.

Zhu, X., Pedrycz, W., Li, Z. (2018). Granular representation of data: A design of families of $\epsilon$ information granules, IEEE Transactions on Fuzzy Systems 26(4), 2107-2119.

Received November 24, 2020, accepted November 28, 2020 